\title{
Oligodendrocyte-Myelin Glycoprotein and Nogo Negatively Regulate Activity-Dependent Synaptic Plasticity
}

\author{
Stephen J. Raiker, ${ }^{1,3}$ Hakjoo Lee, ${ }^{3 \star}$ Katherine T. Baldwin, ${ }^{1 \star}$ Yuntao Duan, ${ }^{1}$ Peter Shrager, ${ }^{4}$ and Roman J. Giger ${ }^{1,2}$ \\ ${ }^{1}$ Department of Cell and Developmental Biology, University of Michigan, Ann Arbor, Michigan 48109, ${ }^{2}$ Department of Neurology, University of Michigan \\ School of Medicine, Ann Arbor, Michigan 48109, 3. Department of Biomedical Genetics, University of Rochester, Rochester, New York 14642, and \\ ${ }^{4}$ Department of Neurobiology and Anatomy, University of Rochester School of Medicine and Dentistry, Rochester, New York 14642
}

In the adult mammalian CNS, the growth inhibitors oligodendrocyte-myelin glycoprotein (OMgp) and the reticulon RTN4 (Nogo) are broadly expressed in oligodendrocytes and neurons. Nogo and OMgp complex with the neuronal cell surface receptors Nogo receptor-1 (NgR1) and paired Ig-like receptor-B (PirB) to regulate neuronal morphology. In the healthy CNS, NgR1 regulates dendritic spine shape and attenuates activity-driven synaptic plasticity at Schaffer collateral-CA1 synapses. Here, we examine whether Nogo and OMgp influence functional synaptic plasticity, the efficacy by which synaptic transmission occurs. In acute hippocampal slices of adult mice, Nogo-66 and 0Mgp suppress NMDA receptor-dependent long-term potentiation (LTP) when locally applied to Schaffer collateral-CA1 synapses. Neither Nogo-66 nor OMgp influences basal synaptic transmission or paired-pulse facilitation, a form of short-term synaptic plasticity. $\mathrm{PirB}^{-1-}$ and $\mathrm{NgR}^{-1-}$ single mutants and $\mathrm{NgR1}^{-1-} ; \mathrm{PirB}^{-1-}$ double mutants show normal LTP, indistinguishable from wild-type controls. In juvenile mice, LTD in $\mathrm{NgR1}^{-1-}$, but not $\mathrm{PirB}^{-1-}$, slices is absent. Mechanistic studies revealed that Nogo-66 and OMgp suppress LTP in an NgR1-dependent manner. OMgp inhibits LTP in part through PirB but independently of $p 75$. This suggests that $\mathrm{NgR} 1$ and PirB participate in ligand-dependent inhibition of synaptic plasticity. Loss of $\mathrm{NgR} 1$ leads to increased phosphorylation of extracellular signal-regulated kinase 1/2 (ERK1/2), signaling intermediates known to regulate neuronal growth and synaptic function. In primary cortical neurons, BDNF elicited phosphorylation of AKT and p70S6 kinase is attenuated in the presence of myelin inhibitors. Collectively, we provide evidence that mechanisms of neuronal growth inhibition and inhibition of synaptic strength are related. Thus, myelin inhibitors and their receptors may coordinate structural and functional neuronal plasticity in CNS health and disease.

\section{Introduction}

Early in postnatal development a number of refinement processes sculpt neuronal connectivity in an experience-dependent manner. A classical example is the formation of ocular dominance (OD) columns in the binocular zone of the primary visual cortex (Katz and Shatz, 1996). During a limited time window called the critical period (CP), experience drives remodeling of synaptic connectivity (Tropea et al., 2009). Beyond the CP, use-dependent changes in neuronal connectivity are less pronounced. More subtle forms of structural neuronal plasticity in the CNS persist throughout adulthood in response to experience, injury, or aging (Florence et al., 1998; Bareyre et al., 2004; Holtmaat and Svoboda, 2009).

Functional synaptic plasticity describes the ability of excitatory synapses to undergo activity-driven long-lasting changes in

\footnotetext{
Received Feb. 18, 2010; revised June 17, 2010; accepted July 25, 2010.

This work was supported by National Research Service Award Ruth Kirschstein Fellowship F31NS061589 (S.J.R.), the New York State Spinal Cord Injury Research Program (P.S. and R.J.G.), Schmitt Program on Integrative Brain Research (P.S.), the Dr. Miriam and Sheldon G. Adelson Medical Foundation on Neural Repair and Rehabilitation, the U.S. Department of Veterans Affairs, and National Institute of Neurological Disorders and Stroke Grant R01 NS047333 (R.J.G.). We thank Marc Rothenberg and Melissa Mingler for PirB mutant mice, Rao Praveen for isolation of $B$ cells, and Margaret Youngman for excellent technical assistance.

${ }^{*} H . L$. and K.T.B. contributed equally to this work.

Correspondence should be addressed to Roman J. Giger, Department of Cell and Developmental Biology, University of Michigan, 109 Zina Pitcher Place, Ann Arbor, MI 48109. E-mail: rgiger@umich.edu.

DOI:10.1523/JNEUROSCI.0895-10.2010

Copyright $\odot 2010$ the authors $\quad 0270-6474 / 10 / 3012432-14 \$ 15.00 / 0$
}

the efficacy of synaptic transmission. This change may be expressed as long-term potentiation (LTP) or long-term depression (LTD). A well characterized system for studying long-lasting changes in synaptic transmission is the Schaffer collateral-CA1 synapse of the hippocampus (Bliss and Collingridge, 1993). Prolonged changes in synaptic activity influence neuronal structure, suggesting that structural and functional neuronal plasticity are linked (Yuste and Bonhoeffer, 2001; Schubert and Dotti, 2007).

Components of the Nogo receptor (NgR1) complex have been implicated in activity-dependent refinement of neuronal connectivity in the healthy CNS. NgR1 associates with the growth inhibitory proteins Nogo, OMgp, and MAG and is the ligand binding component of a receptor complex that includes Lingo-1 and p75 or Troy (Xie and Zheng, 2008). In the visual system, $N g R 1$ and Nogo-A/B participate in the consolidation of neuronal connectivity established during the CP (McGee et al., 2005). In the hippocampus, $\mathrm{NgR} 1$ and $p 75$ regulate dendritic spine morphology (Zagrebelsky et al., 2005; H. Lee et al., 2008). NgR1 also limits activity-dependent synaptic strength at Schaffer collateral-CA1 synapses (H. Lee et al., 2008), and down-regulation of NgR1 expression is required for consolidation of long-term spatial memory (Karlen et al., 2009).

Evidence suggests that neural major histocompatibility complex class 1 (MHC1) molecules and their receptors function in activity-dependent synaptic plasticity and structural modification of synaptic connections (Boulanger, 2009). MHC1 mole- 
cules $H 2-K^{b}$ and $H 2-D^{b}$ are present in the CNS and limit OD plasticity after monocular deprivation (Datwani et al., 2009). Similarly, loss of the MHC1 receptor PirB enhances OD plasticity (Syken et al., 2006). Depletion of MHC1 surface expression results in enhanced LTP and absence of LTD at Schaffer collateralCA1 synapses (Huh et al., 2000). Remarkably, PirB was recently identified as a receptor for Nogo-66, OMgp, and MAG (Atwal et al., 2008). As is the case for NgR1, PirB signals growth cone collapse in response to acutely presented myelin inhibitors in vitro. Moreover, loss of PirB, but not $N g R 1$, results in enhanced neurite outgrowth on substrate-bound myelin inhibitors.

The unexpected convergence of molecular players that limit experience-dependent neuronal plasticity during normal brain maturation and the molecules that inhibit regenerative sprouting after CNS injury suggests that these two processes are related. To explore this idea further, we examined whether the growth inhibitors Nogo and OMgp influence functional synaptic plasticity in adult neural circuits.

\section{Materials and Methods}

Transgenic mice. All animal handling was performed in compliance with local and national animal care guidelines and approved by the University of Rochester Committee on Animal Resources and the University of Michigan Committee on Use and Care of Animals. $\mathrm{NgR} 1, \operatorname{PirB}$, and $p 75$ mutant mice used for our studies have been described previously (K. F. Lee et al., 1992; Ujike et al., 2002; Zheng et al., 2005). The PirB mutant mouse line used in this study carries a null allele (Ujike et al., 2002) and is distinct from the transmembrane domain deletion mutant PirB-TM (Syken et al., 2006). Mice were housed either in the transgenic core facility of the University of Michigan ( $N g R 1$ and PirB colonies) or the University of Rochester ( $N g R 1, \operatorname{PirB}$, and $p 75$ colonies). All mice were kept on a C57BL/ 6 background and housed in a 12-h light-dark cycle. Mice mutant for $\mathrm{NgR} 1$ and $p 75$ were genotyped by PCR analysis of tail biopsies (Venkatesh et al., 2007). Primers for PirB genotyping included PirB-5' 5' $^{\prime}$-GTG GCC TTC ATC CTG TTC CTC-3'; PirB-3', 5' -CCT GGT TAT GGG CTC TTC AGC-3', and PirB-Neo, $5^{\prime}$-CTC GTG CTT TAC GGT ATC GCC-3' and were used as described previously (Ujike et al., 2002).

Reporter gene expression analyses. In NgR1 mutant mice, exon 2 of the $N g R 1$ gene was replaced by a taulacZ reporter cassette (Zheng et al., 2005). For $N g R 1$ reporter gene expression studies, brains from 6- to 8-week-old $N g R 1$ heterozygous mice $\left(N g R 1^{+/ \text {taulacz }}\right)$ were quickly removed and flashfrozen in dry ice-cooled isopentane. Cryosections of forebrain tissue were cut at $25 \mu \mathrm{m}$ and mounted on Superfrost-plus microscope slides (Fisher). Sections were rinsed in PBS ( $137 \mathrm{~mm} \mathrm{NaCl}, 2.7 \mathrm{~mm} \mathrm{KCl}, 1.8 \mathrm{~mm} \mathrm{KH}_{2} \mathrm{PO}_{4}, 1.0$ $\mathrm{mM} \mathrm{Na}_{2} \mathrm{HPO}_{4}$, $\mathrm{pH} 7.4$ ) and developed overnight in $1 \mathrm{mg} / \mathrm{ml}$ 5-bromo-4chloro-3-indolyl- $\beta$-D-galactopyranoside, $5 \mathrm{~mm} \mathrm{~K}_{3} \mathrm{Fe}(\mathrm{CN})_{6}, 5 \mathrm{~mm}$ $\mathrm{K}_{4} \mathrm{Fe}(\mathrm{CN})_{6}$, and $2 \mathrm{~mm} \mathrm{Mg}^{2+}$ in $\mathrm{PBS}$ at $37^{\circ} \mathrm{C}$.

$m R N A$ in situ hybridization. To visualize the mRNA expression pattern of PirB in 3-month-old mouse brain tissue, cryosections $(25 \mu \mathrm{m})$ of wild-type and mutant mice were cut and processed as described previously (Giger et al., 1996). To reduce potential cross-reactivity with PirA transcripts, an antisense PirB cRNA probe directed against the less conserved C-terminal portion of PirB was generated. T7 RNA polymerase was used for in vitro run-off transcription of mouse PirB cDNA (Open BioSystems) from nucleotides 1736-2526. To confirm specificity of the riboprobe, sections of PirB wild-type and mutant brains were processed in parallel.

Isolation of B cells from spleen. The spleens from two adult PirB wildtype and two mutant mice were dissected, and B cells were isolated as described previously (Sojka et al., 2005). Briefly, spleen cells were incubated with anti-Thy1.2 on ice for $40 \mathrm{~min}$. The Thy1.2 alloantigen is expressed on all thymocytes, peripheral T lymphocytes, and some intraepithelial T cells. Guinea pig complement was added for $25 \mathrm{~min}$ at $37^{\circ} \mathrm{C}$ to lyze Thy1.2-positive cells. The B cells were then collected by two subsequent rounds of low-speed centrifugation in a discontinuous Ficoll gradient. The purity of isolated B cells was assessed by flow cytometry
(FACS Diva 6.0). From spleen, 35.4 million and 32.3 million cells were isolated from PirB wild-type and mutant mice, respectively. Cells were sorted by using CD3-Pe and CD4-Pe-Cy7 for T cells and B220-FITC and CD 19-APC to label B cells. The purity of B cells was $74 \%$ for $\mathrm{PirB}^{+/+}$and $84 \%$ for PirB $^{-1-}$ spleen.

Isolation of synaptic density fractions. Preparation of synaptosomes from mouse or rat brain extracts were carried out as described previously (Phillips et al., 2001). Briefly, mouse neocortices and hippocampi from 3- or 8-week-old NgR1 wild-type and mutant mice were dissected. In a separate set of experiments hippocampi from 6- to 7-week-old rats were used. Dissected tissue was homogenized in $0.32 \mathrm{M}$ sucrose containing 0.1 $\mathrm{mm} \mathrm{CaCl}_{2}, 1 \mathrm{~mm} \mathrm{MgCl}$, $0.1 \mathrm{~mm}$ PMSF, $25 \mathrm{~mm} \mathrm{NaF}$, and $1 \mathrm{~mm} \mathrm{Na} \mathrm{VO}_{4}$. Subsequently, $2 \mathrm{M}$ sucrose solution containing $0.1 \mathrm{mM} \mathrm{CaCl}_{2}$ was added to adjust the final concentration to $1.25 \mathrm{M}$ sucrose. In an ultracentrifuge tube, the $1.25 \mathrm{M}$ sucrose solution containing the tissue homogenate was overlaid with a $1 \mathrm{M}$ sucrose solution containing $0.1 \mathrm{mM} \mathrm{CaCl}_{2}$ and with $0.32 \mathrm{M}$ sucrose solution containing $0.1 \mathrm{~mm} \mathrm{CaCl}_{2}$ Synaptosomes were collected at the $1 \mathrm{~m} / 1.25 \mathrm{~m}$ interface of the sucrose gradient by centrifugation at $100,000 \times \mathrm{g}$ for $3 \mathrm{~h}$ in a Sorvall UltraCentrifuge using a SW41 rotor. From the isolated synaptosomes, the extrasynaptic junction fraction was separated from the synaptic junction proteins by extraction in $1 \%$ Triton X-100 at $\mathrm{pH} 6$ followed by centrifugation at $40,000 \times \mathrm{g}$ for 30 min. The resulting pellet comprised the synaptic junction fraction and was further separated into presynaptic and postsynaptic density fractions by extraction in $1 \%$ Triton $\mathrm{X}-100$ at $\mathrm{pH} 8$. The protein concentration of each fraction was determined using the BCA kit (Pierce) and adjusted to the same final value. Synaptic density fractions were aliquoted and stored at $-80^{\circ} \mathrm{C}$. Multiple independent preparations were carried out from NgR1 wild-type and mutant mice at $6-7$ weeks $(n=4)$ and 3 weeks $(n=3)$.

Recombinant proteins. Human embryonic kidney (HEK) 293T cells were transiently transfected using Lipofectamine 2000 (Invitrogen) to express enhanced green fluorescent protein(eGFP) or full-length mouse PirB (Open Biosystems). Soluble fusion proteins contained either human placental alkaline phosphatase (AP) or the $\mathrm{Fc}$ region of human IgG1. Soluble AP-Nogo66 C-terminally tagged with 6-histidines (6his) and AP-Fc were expressed in HEK293T cells and isolated from conditioned cell culture supernatant (optiMEM; Invitrogen) by affinity chromatography using ProteinA/G beads (Pierce) or $\mathrm{Ni}^{2+}$-NTA beads (Invitrogen) as described previously (Venkatesh et al., 2005). Additional recombinant proteins included Nogo66-Fc and OMgp-6his (R\&D Systems). The recombinant proteins were analyzed by SDS-PAGE followed by Western blotting or Coomassie staining. In addition, the quality of recombinant proteins was assayed by binding to COS-7 cells transiently transfected with an expression construct for full-length mouse PirB or eGFP as described previously (Robak et al., 2009).

Primary neuronal cultures. Rat embryonic day 18 (E18) hippocampal and cortical neurons were cultured at high density on poly-L-lysine (50 $\mu \mathrm{g} / \mathrm{ml}$ )-coated six-well plates in NS21 growth medium (Chen et al., $2008)$ at $37^{\circ} \mathrm{C}$ in a humidified cell culture incubator. At day 9 in vitro (DIV9), cultures were treated with BDNF (100 ng/ml), crude CNS myelin $(185 \mu \mathrm{g} / \mathrm{ml})$ (Robak et al., 2009), or AP-Nogo66 (5 nM) final concentration. AP-Nogo-66 in OptiMEM was added to the cultures, and the same volume of OptiMEM was added to control cultures. Cells were lysed for $20 \mathrm{~min}$ on ice using cooled Brij lysis buffer (10 mM potassium phosphate, $\mathrm{pH} 7.2,1 \mathrm{~mm}$ EDTA, $10 \mathrm{mM} \mathrm{MgCl}_{2}$, $50 \mathrm{~mm} \beta$-glycerophosphate, $1 \mathrm{mM} \mathrm{Na}_{3} \mathrm{VO}_{4}, 0.5 \%$ NP40, and $0.1 \%$ Brij- 35 ) containing protease inhibitor mixture (Sigma) at a 1:100 dilution. Cell lysates were cleared by centrifugation in a cooled Eppendorf centrifuge for $10 \mathrm{~min}$ at maximal speed, and the protein concentration of supernatants was determined with the BCA kit. For Western blot analysis, $10 \mu \mathrm{g}$ of protein lysate was loaded per lane.

Western blot analysis. Crude brain homogenates and synaptosomal density fractions were normalized to total protein (BCA kit). Synaptosomes isolated from adult rats or $\mathrm{NgR} 1$ wild-type and mutant mice were lysed in $2 \times$ Laemmli buffer, separated by SDS-PAGE, and transferred onto nylon membranes. Nitrocellulose membranes were blocked with fat-free milk ( $2 \%$ in TBS-T) and probed with antibodies specific for NgR1 (1:1000; R\&D Systems), Lingo-1 (1:1000; R\&D Systems), p75 (1: 1000; Promega), Nogo-A/B (1:500; R\&D Systems), OMgp (1:1000; R\&D Systems), FGFR1 (kind gift from M. K. Stachowiak, University of Buf- 
falo, Buffalo, NY), FRS2 $\alpha$ (1:1000; Santa Cruz Biotechnology), calcium/ calmodulin-dependent protein kinase II $\alpha$ (CamKII $\alpha$ ) (1:1000; Sigma), NR1 (1:1000; Millipore), NR2B (1:1000; Millipore), GluR1 (1:1000; Millipore), syntaxin 1A (1:500; Assay Designs), postsynaptic density-95 (PSD-95) (1:500; Millipore), synaptophysin (1:1000; Sigma), TuJ1 (1: 1000; Promega), human Fc (1:1000; Millipore Bioscience Research Reagents), AP (1:5000; American Research Products), and actin (1;10,000; Sigma). To confirm that PirB mutant mice are null for PirB protein, lysates of spleen $B$ cells were analyzed by Western blotting with a polyclonal goat anti-PirB antiserum (1:250; R\&D Systems). Phospho-specific antibodies and the corresponding phosphorylation-independent antibody were obtained from Cell Signaling and included anti-pAKT(Ser473) (1:2000) and total AKT (1:5000), anti-phosphorylated extracellular signal-regulated kinases 1/2 (p-ERK1/2) (Thr202/Tyr204) (1:2000) and total ERK (1:5000), and anti-pS6K(Thr389) (1:1000) and total S6K (1:1000). To detect all of these antibodies ECL anti-rabbit, anti-goat, or anti-mouse secondary IgGHRP (from donkey; GE Healthcare) at 1:3000 was used. For Western blots with the phospho-specific antibodies, PVDF membrane (from Millipore) was blocked with $2 \%$ TBS-T ( $0.1 \%$ Tween), and the same buffer was used for antibody dilution.

Electrophysiological recordings. Recordings from acute hippocampal slices were performed as described previously (H. Lee et al., 2008). Briefly, for LTP experiments $\mathrm{NgR} 1$, PirB, or $p 75$ mutant and wild-type mice between 6 and 9 weeks of age were decapitated, and the brains were quickly removed and immediately placed in ice-cold artificial CSF (ACSF: $125 \mathrm{~mm} \mathrm{NaCl}, 1.25 \mathrm{~mm} \mathrm{NaH}_{2} \mathrm{PO}_{4}, 25 \mathrm{~mm}$ glucose, $25 \mathrm{~mm}$ $\mathrm{NaHCO}_{3}, 2.5 \mathrm{mM} \mathrm{CaCl}_{2}, 1.3 \mathrm{~mm} \mathrm{MgCl}_{2}, 2.5 \mathrm{~mm} \mathrm{KCl}$ saturated with $95 \%$ $\mathrm{O}_{2} / 5 \% \mathrm{CO}_{2}$ ). For LTD studies brains from postnatal day (P) 15-P17 mice or P18-P21 rat pups were used as described in detail (H. Lee et al., 2008). For all recordings at CA3-CA1 synapses sagittal slices $(400 \mu \mathrm{m})$ were cut on a vibrating microtome and maintained in oxygenated $(95 \%$ $\mathrm{O}_{2} / 5 \% \mathrm{CO}_{2}$ ) ACSF at room temperature for at least $1.5 \mathrm{~h}$. For recordings, the slices were transferred to a heated immersion chamber, continuously perfused at $3 \mathrm{ml} / \mathrm{min}$ with oxygenated ACSF, and maintained at $32 \pm 0.5^{\circ} \mathrm{C}$.

Evoked potentials were recorded from the CA1 stratum radiatum region by stimulating Schaffer collateral afferents with a platinum/iridium concentric bipolar electrode (FHC Inc). Field EPSPs (fEPSPs) were taken with glass microelectrodes filled with ACSF (pipette resistance $\sim 0.3-0.4$ $\mathrm{M} \Omega$ ). The stimulation electrode was positioned in the Schaffer collateral projections to provide activation of the CA1 pyramidal cells. Inputoutput (I/O) curves were established using a stimulus amplitude of 50 , 100 , or $150 \mu \mathrm{A}$. Slices were monitored with stimuli consisting of constant current pulses of $0.1-\mathrm{ms}$ duration at $0.067 \mathrm{~Hz}$. After baseline recording for $\sim 45 \mathrm{~min}(\sim 1-\mathrm{mV}$ amplitude), LTP was induced at $\leq 50 \%$ of maximal amplitude by high-frequency stimulation (HFS) $(100 \mathrm{~Hz}, 1$-s duration, two trains, interval $10 \mathrm{~s}$ ) as described previously (Meng et al., 2003). Slices that did not show a stable baseline for at least 30 min before stimulation were discarded. For local application of recombinant protein to the dendritic field of CA1 neurons, OMgp, Nogo-66, or AP-Fc were diluted in ACSF to a final concentration of $0.5-1 \mathrm{mg} / \mathrm{ml}$, loaded in the recording pipette, and applied locally as described previously (H. Lee et al., 2008). For paired-pulse facilitation (PPF) recordings, interpulse interval durations of $25,50,100,200,300,400$, and 500 ms were used, and recordings in the presence or absence of locally applied ligand were performed as described previously (H. Lee et al., 2008).

LTD experiments were carried out in a similar fashion on acute slices from $\mathrm{P} 15-\mathrm{P} 20$ mouse pups except that $\mathrm{MgCl}_{2}$ and $\mathrm{KCl}$ concentrations were increased to 2.0 and $5.0 \mathrm{~mm}$, respectively (H. Lee et al., 2008). To induce depression of the fEPSP a low-frequency stimulus comprised of 900 pulses given at $1 \mathrm{~Hz}$ for a total duration of 15 min was applied. For local application of recombinant protein to the dendritic field of CA1 neurons, proteins of interest were loaded in the recording electrode as described above.

Data acquisition and analysis. Recorded potentials were filtered at 3 $\mathrm{kHz}$, digitized at $12.5 \mathrm{kHz}$, and stored for later analysis. fEPSPs were analyzed by fitting third-order polynomials to the sweeps, first to measure the peak, and then to measure the slope at the $50 \%$ amplitude point. All fits were monitored visually on the oscilloscope screen. Data were normalized to the baseline average. Electrophysiological measurements are presented as mean percentile of baseline \pm SEM. Data were analyzed statistically using Student's $t$ test. Significance was determined as $p<0.05$.

\section{Results}

Reporter gene expression analyses reveal $\mathrm{NgR} 1$ promoter activity in hippocampal CA1 pyramidal cells and dentate granule neurons

Previous studies showed that loss of $\mathrm{NgR} 1$ results in a dendritic spine phenotype in adult hippocampal CA1 neurons. Compared with age-matched wild-type mice, the spine morphology profile of $\mathrm{NgR} 1$ mutants appears more immature, indicating that $\mathrm{NgR} 1$ functions in dendritic spine maturation or stabilization (H. Lee et al., 2008). Electrophysiological studies further revealed that $N g R 1$ is important for the induction and expression of LTD and FGF2dependent regulation of LTP at Schaffer collateral-CA1 synapses (H. Lee et al., 2008). To assess NgR1 expression in the adult mouse brain, we took advantage of an existing $N g R 1^{\text {taulac } Z}$ reporter mouse (Zheng et al., 2005). Consistent with $\mathrm{NgR} 1 \mathrm{mRNA}$ expression studies (Hunt et al., 2002; Josephson et al., 2003; Barrette et al., 2007), taulac $Z$ reporter gene expression was strongest in the hippocampus, neocortex, dorsal thalamus, basolateral amygdala, and superficial layers of the piriform cortex (Fig. $1 A$ ). In addition, $\beta$-galactosidase labeling was detected in several major fiber systems, indicating that the $N g R 1$ promoter is active in different types of CNS projection neurons. Fiber systems with strong labeling included the optic tract, corpus callosum, internal capsule, fimbria, and fornix (Fig. 1A). In the hippocampus, strong labeling was detected in the CA1 dendritic field, the alveus, and presumptive fibers of the temporoammonic pathway. The temporoammonic pathway to CA1 provides input directly from layer III of the entorhinal cortex onto distal dendrites of CA1 pyramidal cells in the stratum lacunosum moleculare (Fig. $1 B$ ). Somewhat weaker labeling was observed in the outer rim of the molecular layer of the dentate gyrus and along dentate mossy fiber projections (Fig. $1 A, B$ ). Very little, if any, $\beta$-galactosidase activity was detected in the CA3 pyramidal cell layer and Schaffer collaterals (Fig. $1 \mathrm{~B}$ ). Together, these findings reveal that the $\mathrm{NgR} 1$ promoter is active in distinct regions of the mature brain and suggest that NgR1 is expressed in specific populations of CNS projection neurons. In the hippocampus strongest labeling was detected in CA1 pyramidal cells and axons of the temporoammonic pathway.

\section{OMgp and Nogo-A, but not Nogo-B, are present in presynaptic and postsynaptic density fractions}

Although most attention has focused on the role of Nogo-A and OMgp as myelin-derived inhibitors of axonal growth and regeneration after CNS injury, Nogo-A and OMgp expression is not confined to oligodendrocytes. OMgp and Nogo-A are abundantly found in various types of neurons in the developing and mature CNS (Josephson et al., 2001; Huber et al., 2002; H. Lee, et al., 2008; J. K. Lee et al., 2009; Gil et al., 2010). Ultrastructural analyses revealed that Nogo-A and NgR1 are present at presynaptic and postsynaptic sites in the mature rat neocortex (Wang et al., 2002). In addition, NgR1 and Nogo-A were found in synaptosomal density fractions prepared from juvenile and adult rat hippocampus (H. Lee et al., 2008; Grunewald et al., 2009). Similarly, a synaptic association for OMgp in mouse forebrain has been reported (Gil et al., 2009). PirB, a recently discovered receptor for Nogo, OMgp, and MAG, is expressed in the CNS (Atwal et al., 2008) and was found in synaptosomes isolated from whole mouse brain extracts (Syken et al., 2006). Double-immunofluorescence labeling of 

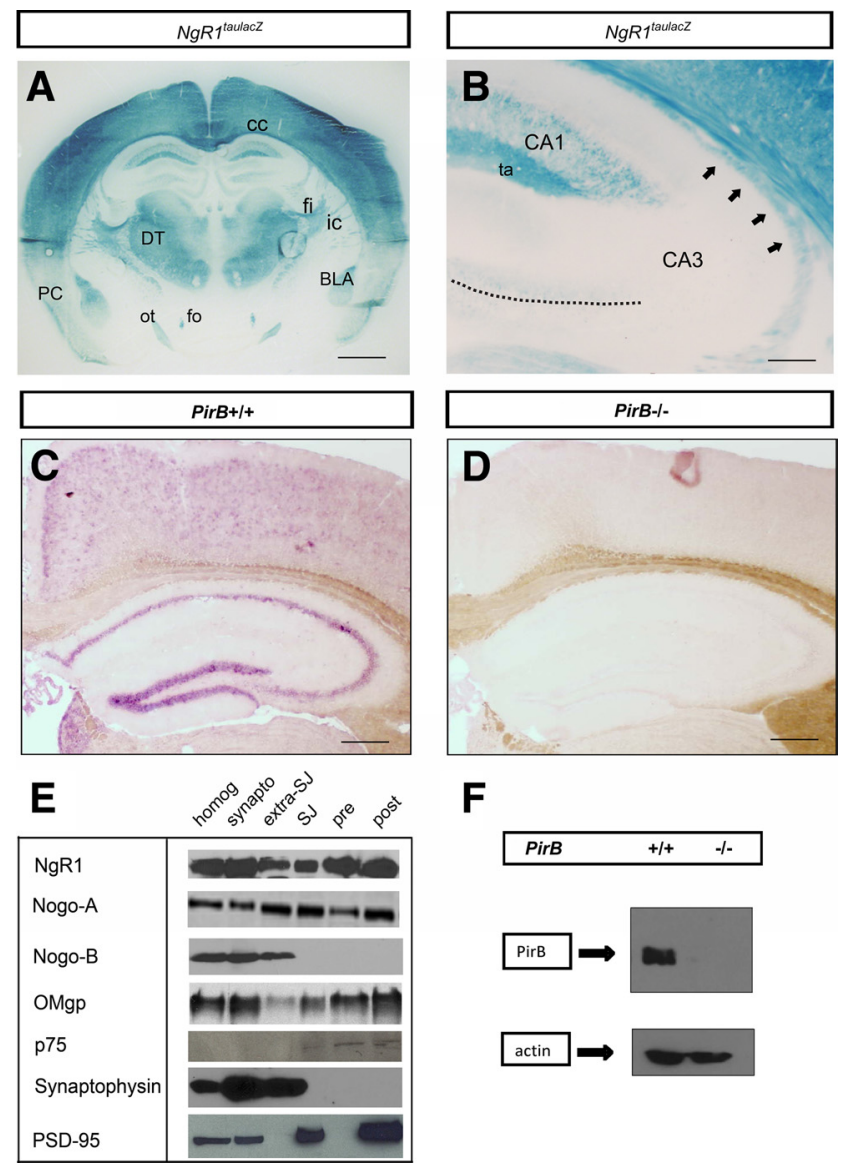

Figure 1. Distribution of myelin inhibitors and their receptors in brain. $\boldsymbol{A}, \mathrm{NgR} 1^{+/ t a u l a c z}$ reporter gene expression analysis of coronal brain tissue section. Strong $\beta$-galactosidase staining is observed in the neocortex, dorsal thalamus (DT), superficial layers of the piriform cortex $(\mathrm{PC})$, and basolateral amygdala (BLA). Several major fibers systems show strong $\beta$-galactosidase staining including the internal capsule (ic), corpus callosum (cc), optic tract (ot), fimbria (fi), and fornix (fo). $\boldsymbol{B}$, Higher magnification of the hippocampus shows labeling of the dendritic field of CA1 pyramidal neurons, fibers of the temporoammonic pathway (ta), alveus (arrows), and presumptive mossy fiber projections (dotted line). Of note, no reporter gene expression was observed in the CA3 pyramidal cell layer or Schaffer collateral projections. C, In situ hybridization with an antisense PirB probe shows weak labeling in the adult mouse neocortex. Higher levels of PirB expression are observed in the dentate gyrus and CA3-CA1 pyramidal layer. $D$, The same Pir $B$ antisense probe shows no labeling on

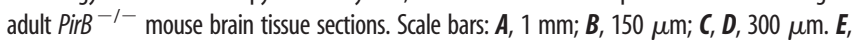
Distribution of NgR1, Nogo-A, Nogo-B, OMgp, and p75 in synaptic density fractions prepared from adult rat hippocampi. Markers for different synaptic factions included synaptophysin and PSD-95. Abbreviations: homog, hippocampal homogenate; synapto, synaptosmal fraction; extra-SJ, extrasynaptic junction; SJ, synaptic junction; pre, presynaptic fraction; post, postsynaptic fraction. F, Anti-PirB immunoblotting of $B$ cells isolated from WT or PirB ${ }^{-1-}$ spleen. No PirB protein is detected in Pir $^{-1-}$ spleen homogenates. Anti-actin is shown as a loading control.

primary cortical neurons revealed that PirB is present at or near synaptic sites (Syken et al., 2006).

To independently assess the distribution of PirB in the neocortex and hippocampus, we performed in situ hybridization to visualize PirB transcripts in adult mouse brain tissue. In the hippocampus, dentate granule cells are labeled and somewhat less intense staining is found in CA3 and CA1 neurons. Weak labeling was found in the adult neocortex. As a specificity control, brain sections of age-matched PirB mutants were processed in parallel. No labeling was detected in brain tissue sections of PirB mutants (Fig. 1C,D). Consistent with a previous report (Ujike et al., 2002), these PirB mutants are null for PirB. No PirB protein was detected by Western blot analysis of mutant B cells (Fig. 1F).
Next, we assessed the subcellular distribution of Nogo-A, Nogo-B, OMgp, and p75 in the hippocampus compared with $\mathrm{NgR} 1$. Synaptosomes were isolated from adult rat hippocampal homogenates and then further separated into synaptic density fractions (Fig. 1E). To ensure the quality of the biochemical fractionation, antibodies specific for the synaptic markers synaptophysin (extrasynaptic junction) and PSD-95 (postsynaptic fraction) were used. As shown in Figure $1 E$, NgR1, Nogo-A, and OMgp are abundantly present in presynaptic and postsynaptic density fractions. Nogo-B is abundant in brain homogenates, synaptosomes, and extrasynaptic junction fractions, but is absent from synaptic junction and presynaptic and postsynaptic density fractions. This suggests that only Nogo-A, but not the splice variant Nogo- $\mathrm{B}$, is present at hippocampal synapses. Consistent with a previous report (Barrett et al., 2005), p75 is very sparsely expressed in the mature rat hippocampus and largely confined to septo-hippocampal fibers. Collectively, these studies show that Nogo-A and OMgp and their high-affinity binding partners, NgR1 (H. Lee et al., 2008) and PirB (Syken et al., 2006), are expressed in the adult brain and localized to synaptic and extrasynaptic sites. Nogo-A and OMgp are found in presynaptic and postsynaptic density fractions, and both proteins appear to be somewhat enriched postsynaptically. Thus, biochemical studies are consistent with the idea that Nogo-A, OMgp, NgR1, and PirB are present at synaptic sites where they may interact with each other to influence synaptic function.

\section{OMgp inhibits LTP after tetanic stimulation}

Thus far, our studies indicate that Nogo-A and OMgp are expressed in the hippocampus and present in presynaptic and postsynaptic density fractions. These findings, coupled with our previous observation that $N g R 1$ functions as a FGF2-dependent regulator of hippocampal LTP at CA3-CA1 synapses (H. Lee et al., 2008), prompted us to investigate whether NgR1 ligands other than FGF2 have the potential to modulate synaptic plasticity. In a first set of experiments, recombinant OMgp was locally applied to Schaffer collateral-CA1 synapses of acute hippocampal slices prepared from adult wild-type mice. After baseline recording for $>30 \mathrm{~min}$, LTP was induced by two trains of HFS (100 $\mathrm{Hz}$; $1 \mathrm{~s}$; separated by a 10-s interval), which resulted in a sustained increase in the slope of the fEPSP. The mean fEPSP slope 55-60 min after HFS was measured as a percentage of baseline. In the absence of exogenously applied ligand, LTP of synaptic transmission in wild-type mice was robust and stable at $171 \pm 2 \%$ compared with baseline (100\%). The LTP recorded is NMDA receptor (NMDAR)dependent because it is blocked completely in the presence of the NMDAR antagonist 2-amino-5-phosphonovalerate (50 $\mu \mathrm{M})$ added to the slice perfusion solution (data not shown).

Analogous to our previous experiments with FGF2 (H. Lee et al., 2008), soluble OMgp was loaded into the recording pipette and locally applied to the dendritic field of CA1 neurons. In the presence of OMgp, LTP in response to HFS was significantly decreased (fEPSP: $130 \pm 8 \% ; p<0.05$ ) compared with no-ligand control slices (Fig. $2 \mathrm{~A}$ ). As an additional control, human placental alkaline phosphatase fused to the Fc region of human IgG1 $(\mathrm{AP}-\mathrm{Fc})$, was locally applied via the recording electrode to the dendritic field of CA1 neurons (Fig. 2B). As was the case for no-ligand control slices, LTP at 55-60 min after HFS in APFc-treated slices was robust (fEPSP: $162 \pm 6 \%$ ) and significantly higher compared with OMgp-treated slices $(p<0.05)$ (Fig. 2C). Together, these results show that OMgp attenuates activity-dependent synaptic strength at Schaffer collateralCA1 synapses. 
Next, to examine whether acute treatment with OMgp had a direct effect on basal neurotransmission, we assessed basal synaptic function by constructing $\mathrm{I} / \mathrm{O}$ curves in the presence or absence of locally applied OMgp. I/O curves were generated by measuring fEPSP evoked by stimulation of Schaffer collateral projections with different stimulus intensities. As shown in Figure 2D, the application of OMgp had no effect on the single stimulus-evoked responses across the range of stimuli tested. This suggests that acute application of OMgp does not significantly alter basal synaptic transmission.

Because OMgp is present in presynaptic and postsynaptic density fractions (Fig. $1 E)$, it is not apparent whether OMgp functions presynaptically or postsynaptically at the CA3-CA1 synapse. To address whether OMgp is likely to influence presynaptic function, we measured PPF in the presence or absence of exogenously applied OMgp. PPF is a presynaptically driven form of short-term plasticity that measures transient enhancement of neurotransmitter release induced by two closely spaced stimuli attributable to accumulation of intracellular calcium (Schulz et al., 1994). We measured PPF at interstimulus intervals of $25-500 \mathrm{~ms}$ and observed maximal facilitation at time intervals between 25 and $100 \mathrm{~ms}$. Upon exposure to OMgp, no significant difference $(p>0.05)$ was observed in PPF at any interstimulus interval tested (Fig. 2E,F). This indicates that OMgp does not influence the presynaptic neurotransmitter release probability and suggests that OMgp functions via a postsynaptic mechanism to attenuate LTP of synaptic transmission.

\section{OMgp does not alter induction or expression of LTD}

LTP and LTD of synaptic transmission are reciprocal forms of long-lasting changes in synaptic activity that adapt neuronal transmission to external experience. In response to high levels of synaptic activity, a synapse can increase both the level of neurotransmitter release and the amplitude of the postsynaptic response. Conversely, low-frequency stimulation (LFS) over several minutes can result in weakening or depression of synaptic activity. Because $N g R 1$ is important for the expression of LTD at CA3-CA1 synapses (H. Lee et al., 2008), we wondered whether OMgp influences synaptic plasticity of the LTD type. LTD of synaptic transmission was induced in acute hippocampal slices from P18-P21 rat pups by LFS at $1 \mathrm{~Hz}, 900$ pulses. In no-ligand control slices, LFS resulted in a prolonged $(>1 \mathrm{~h})$ and significant depression of the fEPSP slope compared with baseline $(79 \pm 3 \% ; p<$ 0.05) (Fig. 2G). As was the case for no-ligand control slices, hippocampal slices locally treated with OMgp showed a significant $(p<0.05)$ and lasting decrease in their fEPSP slope $(84 \pm 5 \%)$ (Fig. 2G). Quantification of LTD at 55-60 min after LFS re-
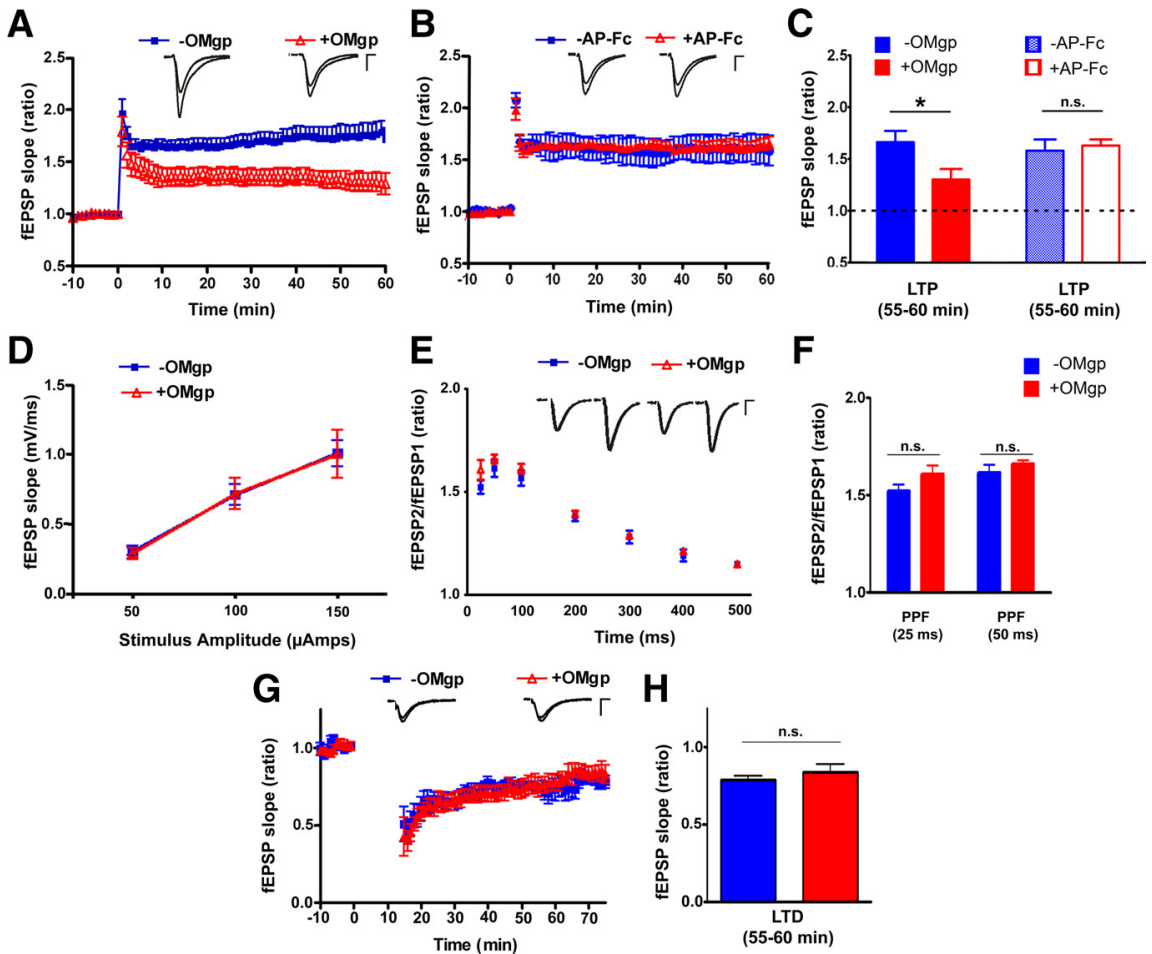

Figure 2. OMgp inhibits hippocampal LTP. Recordings of fEPSPs at Schaffer collateral-CA1 synapses in acute hippocampal slices of 6-to 8-week-old wild-type mice. $A$, Slices were treated with $0 \mathrm{Mgp} \mathrm{locally} \mathrm{applied} \mathrm{via} \mathrm{the} \mathrm{recording} \mathrm{pipette} \mathrm{to} \mathrm{the} \mathrm{dendritic}$ field of CA1 neurons. Summary of LTP recordings in the absence ( $-0 \mathrm{Mgp}$; blue squares) or presence (+0Mgp; red triangles) of $171 \pm 2 \%$ of baseline ( $n=8$ slices $/ 6$ animals). In the presence of $0 \mathrm{Mgp}$, the mean fEPSP at $55-60$ min was $130 \pm 8 \%$ of baseline $n=6$ slices/3 animals). The concentration of OMgp in the recording electrode was $1 \mathrm{mg} / \mathrm{ml}$. B, In parallel experiments, hippocamanimals), and in the presence of AP-Fc, the mean fEPSP at $55-60 \mathrm{~min}$ is $162 \pm 6 \%$ of baseline ( $n=7$ slices $/ 5$ animals). Insets, Representative traces collected before and after HFS are shown. B, C, Quantification of LTP at 55- 60 min after HFS in the presence 05. All error bars are SEMs. $D, 1 / 0$ curves for basal synaptic transmission revealed no differences in fEPSP amplitudes between lices treated with 0Mgp ( $n=9$ slices/4 animals) compared with untreated (no-ligand) slices ( $n=6$ slices/4 animals). E, PPF in fints an interpulse interval of $50 \mathrm{~ms}$. $\boldsymbol{F}$, Ouantification of PPF experiments. The increase in the second fEPSP 作

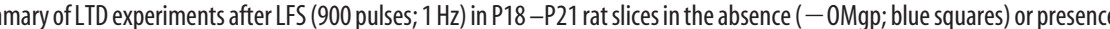
(triangles) of OMgp applied via the recording electrode. Evoked fEPSP slope ratios are shown as a function of time. $3 \%$ of baseline ( $n=5$ slices/3 animals) and in the absence of OMgp (blue squares) the mean fEPSP was $84 \pm 5 \%$ of baseline ( $n=$ 3 slices/2 animals). For insets in $\boldsymbol{A}, \boldsymbol{B}, \boldsymbol{E}$, and $\boldsymbol{G}$, calibration is $0.5 \mathrm{mV}, 5 \mathrm{~ms}$. $\boldsymbol{H}$, Quantification of LTD at $55-60 \mathrm{~min}$ after LFS (blue: no OMgp; red: 0 Mgp was locally applied). n.s. indicates not significant; $p>0.05$. Error bars are SEMs.

vealed no statistically significant difference between OMgp and no-ligand treated slices $(p=0.88)$ (Fig. $2 H$ ). These results indicate that in the presence of acutely applied OMgp LTD at CA3-CA1 synapses is not altered. In sum, the data suggest that in wild-type hippocampal slices OMgp inhibits LTP-type, but not LTD-type, synaptic plasticity.

\section{Nogo-66 functions as a negative regulator of hippocampal LTP}

Like OMgp, Nogo-A is present at synapses (Wang et al., 2002; H. Lee et al., 2008). To examine whether the Nogo inhibitory peptide Nogo-66 influences functional synaptic plasticity, soluble Nogo-66 was loaded into the recording pipette and locally ap- 

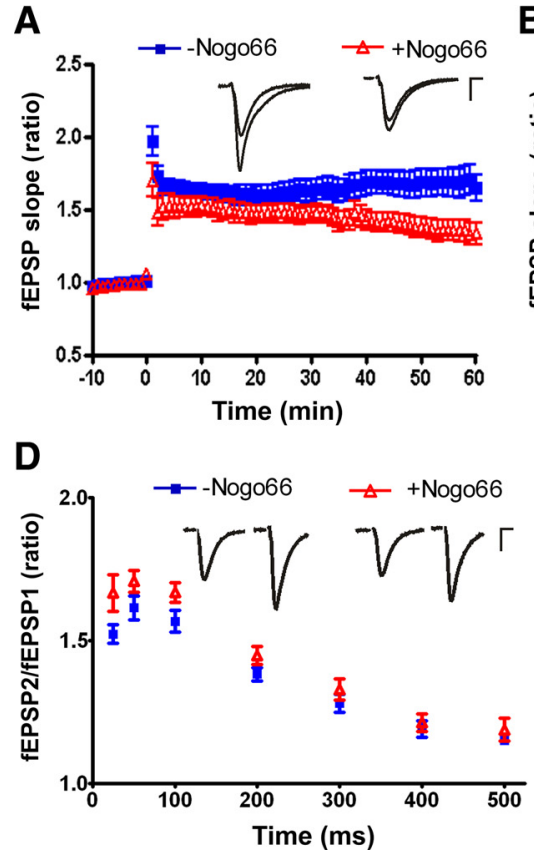
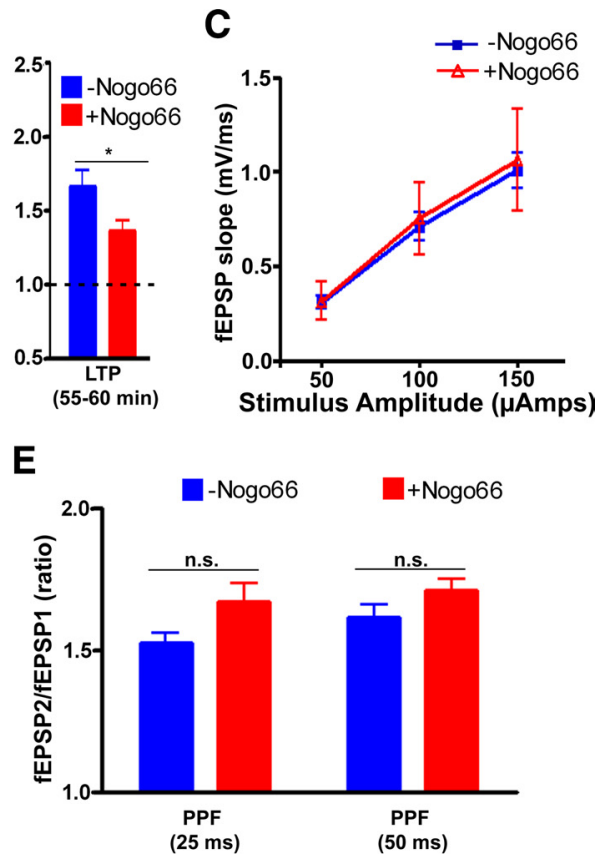

Figure 3. Nogo-66 inhibits LTP. A, Nogo- 66 was loaded into the recording pipette $(1 \mathrm{mg} / \mathrm{ml})$ and locally applied to the dendritic field of CA1 neurons. Summary of LTP recordings after tetanic stimulation ( $t=0 \mathrm{~min}$ ) of hippocampal slices in the absence (blue squares) or presence (red triangles) of acutely applied Nogo-66 is shown. Nogo-66-treated slices (mean fEPSP, $136 \pm 7 \%, n=11$ slices/9 animals) show significantly decreased LTP $(p<0.05)$ compared with no-ligand slices (mean fEPSP, $171 \pm 2 \%$ of baseline, $n=8$ slices/ 6 animals). Insets, Representative traces before and after HFS are shown. Calibration is $0.5 \mathrm{mV}, 5 \mathrm{~ms} . \boldsymbol{B}$, Quantification of LTP at 55-60 min after HFS in the absence (blue) or presence (red) of Nogo-66 revealed a significant decrease in LTP. Baseline is indicated by a dotted line. C, Acutely applied Nogo-66 does not alter basal synaptic transmission at Schaffer collateral-CA1 synapses. I/0 curves were constructed in the absence ( - Nogo66; blue squares) or presence (+Nogo66; red triangles) of Nogo-66 and do not show a significant difference at any stimulus amplitude tested ( $n=7$ slices/4 animals). D, PPF in wild-type slices in the absence ( - Nogo-66; blue squares) or presence (+Nogo-66; red triangles) of Nogo-66. The increase in the second fEPSP amplitude over the first fEPSP amplitude was calculated in the presence or absence of locally applied Nogo-66, and the mean values were plotted against different interpulse intervals $(25-500 \mathrm{~ms})$. No significant difference was observed at any of the interpulse intervals. Insets show traces collected from experiments with an interpulse interval of $50 \mathrm{~ms}$. Calibration is $0.5 \mathrm{mV}$, $5 \mathrm{~ms}$. $\boldsymbol{E}$, Quantification of PPF ratios at 25 and $50 \mathrm{~ms}$ in the absence (blue) or presence (red) of Nogo-66 is shown. Statistical analysis was performed using Student's $t$ test. * indicates significance, $p<0.05$. n.s. indicates not significant. All error bars are SEMs.

$N g R 1$ does not alter the induction or maintenance of LTP at the CA3-CA1 synapse in acute hippocampal slices (H. Lee et al., 2008). Furthermore, overexpression of $N g R 1$ in hippocampal neurons does not lead to significantly altered LTP at CA3CA1 synapses (Karlen et al., 2009). As shown previously (H. Lee et al., 2008), HFS of Schaffer collaterals in acute hippocampal slices of $\mathrm{NgR}^{-/-}$mice leads to robust LTP (fEPSP: $170 \pm 8 \%$ ) that is indistinguishable from LTP observed in age-matched wild-type $\left(\mathrm{NgR} 1^{+/+}\right)$slices (fEPSP: $171 \pm 2 \%$ ). We tested acute treatment of $\mathrm{NgR}^{-1-}$ hippocampal slices with either OMgp or Nogo-66 and found that these ligands no longer result in a significant decrease in LTP (Fig. $4 A-D$ ). In $N g R 1^{-1-}$ slices, tetanic stimulation in the presence of OMgp (fEPSP: $159 \pm 10 \%$ ) and Nogo-66 (fEPSP: $175 \pm 12 \%$ ) results in synaptic potentiation levels comparable with those observed from recordings of $\mathrm{NgR}^{+/+}$slices (fEPSP: $171 \pm 2 \%$ ) or $N g R 1^{-/-}$slices without acutely applied ligand (fEPSP: $170 \pm 8 \%$ ). Statistical analyses revealed that neither OMgp ( $p=$ $0.37)$ nor Nogo-66 ( $p=0.46)$ causes a significant decrease in LTP in $\mathrm{NgR}^{-1-}$ mutant slices (Fig. $4 B, D$ ). Thus, our experiments indicate that OMgp- and Nogo-66-mediated inhibition of hippocampal LTP is NgR1-dependent. Collectively, these observations suggest that NgR1 functions as a neuronal receptor for Nogo and OMgp, eliciting a suppression of activity-dependent synaptic strength. plied to the CA1 dendritic field of pyramidal cells in acute mouse hippocampal slices. Like OMgp, focal application of Nogo-66 leads to a significant suppression of LTP (fEPSP; $136 \pm 7 \%$, compared with control slices (fEPSP; $171 \pm 2 \%$; $p<0.05$ ) (Fig. $3 A, B)$. Additional experiments showed that Nogo-66 has no apparent effect on basal synaptic transmission as assessed by comparing I/O curves constructed in the presence or absence of locally applied Nogo-66 (Fig. 3C). PPF ratios were indistinguishable between no-ligand and Nogo-66-treated slices, indicating that Nogo-66 does not influence the presynaptic neurotransmitter release machinery (Fig. 3D,E). These data suggest that neither OMgp nor Nogo-66 influences PPF, a form of presynaptically driven shortterm plasticity. Thus, the inhibitory effects of Nogo-66 and OMgp on LTP are likely to be the result of postsynaptic mechanisms. Collectively, our studies uncover a novel function for OMgp and Nogo-66 at CNS synapses. In addition to their roles in limiting neuronal growth and sprouting, OMgp and Nogo-66 have the capacity to inhibit activity-driven synaptic plasticity of the LTP type.

\section{OMgp and Nogo-66 suppress LTP in a}

\section{NgR1-dependent manner}

To explore the possibility that OMgp and Nogo-66 suppress LTP in an NgR1-dependent manner, recordings were repeated with hippocampal slices prepared from 6-to 8-week-old NgR1 mutant $\left(\mathrm{NgR} 1^{-1-}\right)$ mice. Previously, we reported that genetic ablation of

\section{p75-independent mechanisms for OMgp-mediated suppression of LTP}

NgR1 is a glycosylphosphatidylinositol-anchored membrane protein and thus depends on interactions with transmembranespanning proteins to convey a signal across the neuronal plasma membrane upon ligand binding. The low-affinity neurotrophin receptor p75 complexes with NgR1, and in some neurons p75 is important to signal myelin inhibition of neurite outgrowth (Yiu and $\mathrm{He}, 2006$ ). Like $\mathrm{NgR} 1$ mutants, acute slices derived from $p 75$ mutant mice show a deficit in the induction of LTD without any changes in LTP (Woo et al., 2005). To test directly whether p75 plays a role in OMgp-mediated suppression of hippocampal LTP, OMgp was focally applied to the CA1 dendritic field of acute hippocampal slices of $p 75$ wild-type $\left(p 75^{+/+}\right)$and mutant $\left(p 75^{-1-}\right)$ mice. As was the case for wild-type slices treated with OMgp (fEPSP: $130 \pm 3 \%$ ), $p 75^{-1-}$ slices treated with OMgp (fEPSP: $127 \pm 2 \%$ ) showed significantly lower levels of synaptic potentiation than slices treated with ACSF only (fEPSP: $166 \pm$ $11 \%)$. Compared with no-ligand control slices, LTP in the presence of OMgp was significantly decreased for both $p 75^{+/+}(p<$ $0.05)$ and $p 75^{-1-}(p<0.05)$ hippocampal slices (Fig. $\left.4 E, F\right)$. Together, our results show that OMgp-mediated suppression of LTP is NgR1-dependent and p75-independent. Thus, with respect to myelin inhibitor-mediated suppression of LTP in CA1 
neurons our mechanistic studies revealed that $N g R 1$ and $p 75$ function can be dissociated.

\section{Normal LTP in PirB mutant mice}

PirB is a receptor for Nogo, MAG, and OMgp that mediates neurite outgrowth inhibition in vitro (Atwal et al., 2008). In the immune system, PirB functions as an inhibitory MHC class I receptor on B cells and myeloid cells (Takai, 2005). Mice deficient for $\beta 2 m / T A P 1$ show markedly reduced surface expression of most MHC1 molecules (Dorfman et al., 1997), and their hippocampal LTP at CA3-CA1 synapses is enhanced, whereas LTD is absent (Huh et al., 2000). These experiments provide indirect evidence that $\mathrm{MHC1}$ molecules are important regulators of activity-dependent synaptic strength. Multiple MHC1 receptors have been identified, several of which are prominently expressed in the CNS (Corriveau et al., 1998). Loss of the MHC1 receptor component $\mathrm{CD} 3 \zeta$ leads to an enhancement of LTP and loss of LTD (Huh et al., 2000). Whether loss of PirB or other MHC1 receptors results in impaired hippocampal plasticity has not yet been examined. Because PirB is expressed in the adult hippocampus (Fig. 1) and several of its ligands have been implicated in activity-dependent regulation of synaptic plasticity, including OMgp (Fig. 2), Nogo (Fig. 3), and MHC1 (Huh et al., 2000), we wanted to assess whether LTP at Schaffer-collateral CA1 synapses is altered between $\operatorname{PirB}$ wild-type $\left(\mathrm{PirB}^{+/+}\right)$ and mutant $\left(\mathrm{PirB}^{-l-}\right)$ mice.

Basal transmission at Schaffer collateral-CA1 synapses was indistinguishable between slices prepared from PirB $^{+/+}$and age-matched $\operatorname{PirB}^{-1-}$ mice as assessed by I/O curves. No changes in single stimulusevoked responses were observed between the two genotypes, suggesting that loss of PirB does not influence basal synaptic transmission (Fig. 5A). PPF, a presynaptially driven form of short-term plasticity, is indistinguishable between $\operatorname{PirB}^{+/+}$and agematched $\mathrm{PirB}^{-1-}$ hippocampal slices. As shown in Figure 5B, PPF ratios were plotted over a stimulus interval of $25-500 \mathrm{~ms}$. The strongest facilitation occurred between 50 and $100 \mathrm{~ms}$. No significant difference in PPF was observed between $\mathrm{PirB}^{+/+}$and $\mathrm{Pir} \mathrm{B}^{-/-}$slices at any of the tested interpulse intervals (Fig. 5B,E) ( $p>0.05)$.

To examine whether loss of PirB influences activity-driven synaptic plasticity, tetanus-induced LTP was recorded from acute hippocampal slices of 6- to 8-week-old $\mathrm{PirB}^{+/+}$and $\mathrm{PirB}^{-1-}$ mice. LTP at CA3-CA1 synapses was induced by two bursts of HFS (100 Hz; $1 \mathrm{~s}$; separated by a 10-s interval), and potentiation at 55-60 min past HFS was quantified (Fig.

E
NgR1-/-
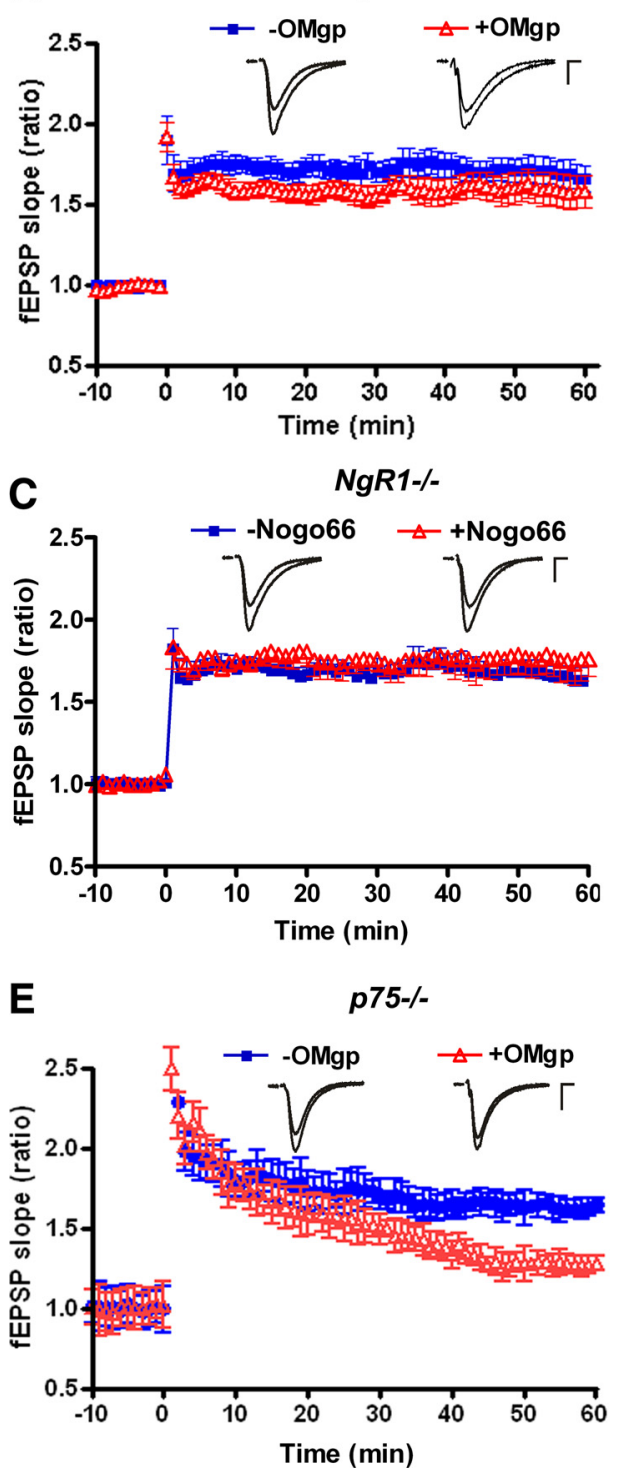

Figure 4. OMgp and Nogo66 suppress LTP in an NgR1-dependent manner. A, C, Summary of LTP recordings after HFS ( $t=0 \mathrm{~min}$ ) of acute hippocampal slices of 6- to 8-week-old $\mathrm{NgR}^{-1-}$ mice in the absence (blue squares) or presence (red triangles) of acutely applied 0Mgp (A) or Nogo-66 (C). B, D, Mean fEPSPs 55-60 min after HFS from NgR1 ${ }^{-1}$ slices $+0 \mathrm{Mgp}(\boldsymbol{B})$ (fEPSP $159 \pm 10 \%$ of baseline, $n=5$ slices $/ 3$ animals) or $+\operatorname{Nog} 066$ (D) (fEPSP $175 \pm 12 \%$ of baseline, $n=$ 6 slices/4 animals) are not significantly different from untreated slices (fEPSP $170 \pm 8 \%$ of baseline, $n=6$ slices/4 animals). $\boldsymbol{E}$, Summary of LTP recordings after HFS $\left(t=0 \mathrm{~min}\right.$ ) of acute hippocampal slices of 6 - to 8 -week-old $p 75^{-1-}$ mice treated with OMgp. In the presence of OMgp (red triangles), LTP is suppressed compared with no-ligand controls (blue squares). $\boldsymbol{A}, \boldsymbol{C}, \boldsymbol{E}$, representative traces before and after HFS are shown as Insets. Calibration is $0.5 \mathrm{mV}, 5 \mathrm{~ms} . \boldsymbol{F}, \operatorname{In} p 75^{-/-}$ slices treated with OMgp (red triangles; mean fEPSP $127 \pm 2 \%$ of baseline, $n=4$ slices $/ 2$ animals) LTP is suppressed compared with no-ligand controls (blue squares; mean fEPSP $166 \pm 11 \%$ of baseline, $n=4$ slices $/ 2$ animals). Mean fEPSPs for wild-type $\left(p 75^{+/+}\right.$) slices treated without (blue) or with (red) OMgp are fEPSP $171+14 \%, n=3$ slices $/ 2$ animals; and fEPSP $130+3 \%, n=4$ slices/3 animals, respectively. $\boldsymbol{B}, \boldsymbol{D}, \boldsymbol{F}$, Quantification of LTP at $55-60$ min after HFS in the absence (blue bars) or presence (red bars) of OMgp is shown. Baseline is indicated by a dotted line. Statistical analysis was performed using Student's $t$ test. $*$ indicates significance; $p<0.05$. All error bars are SEMs.
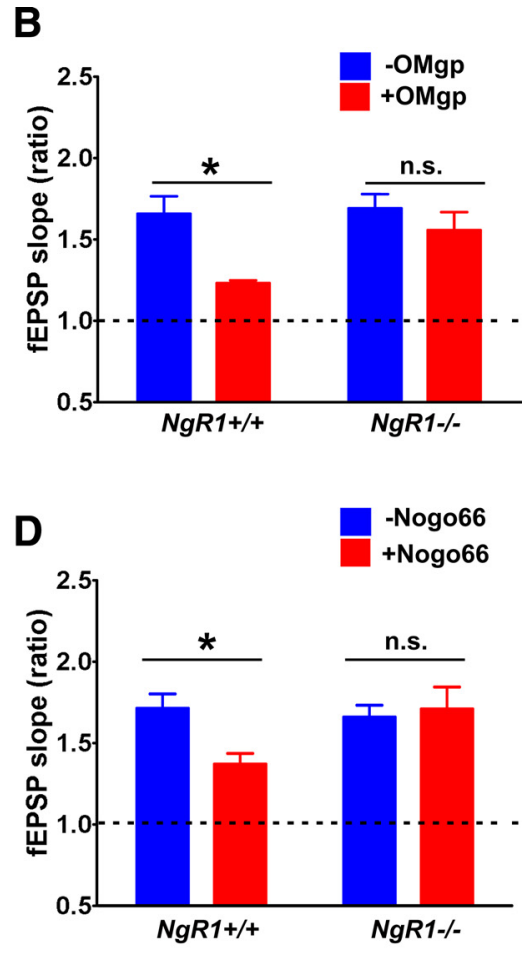

$\mathbf{F}$

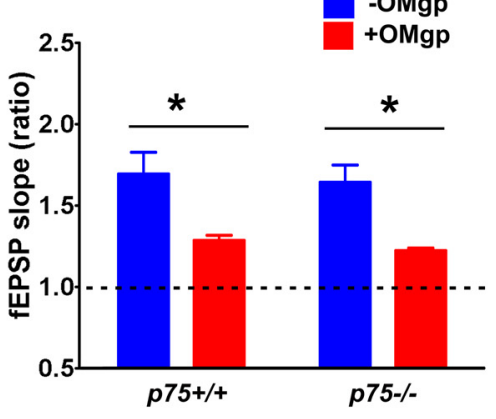

5C,D). Interestingly, LTP of PirB mutants (fEPSP: $157 \pm 6 \%$ ) was robust and indistinguishable from that of PirB wild-type mice (fEPSP: $157 \pm 8 \%$ ) (Fig. $5 C, p=0.99$ ). These data reveal that loss of PirB does not result in altered LTP at CA3-CA1 synapses. Thus, loss of PirB does not mimic the enhanced LTP phenotype reported for $\beta 2 \mathrm{~m} / \mathrm{TAP} 1$ double mutants, mice with greatly reduced surface expression of $\mathrm{MHC1}$ molecules (Huh et al., 2000). 

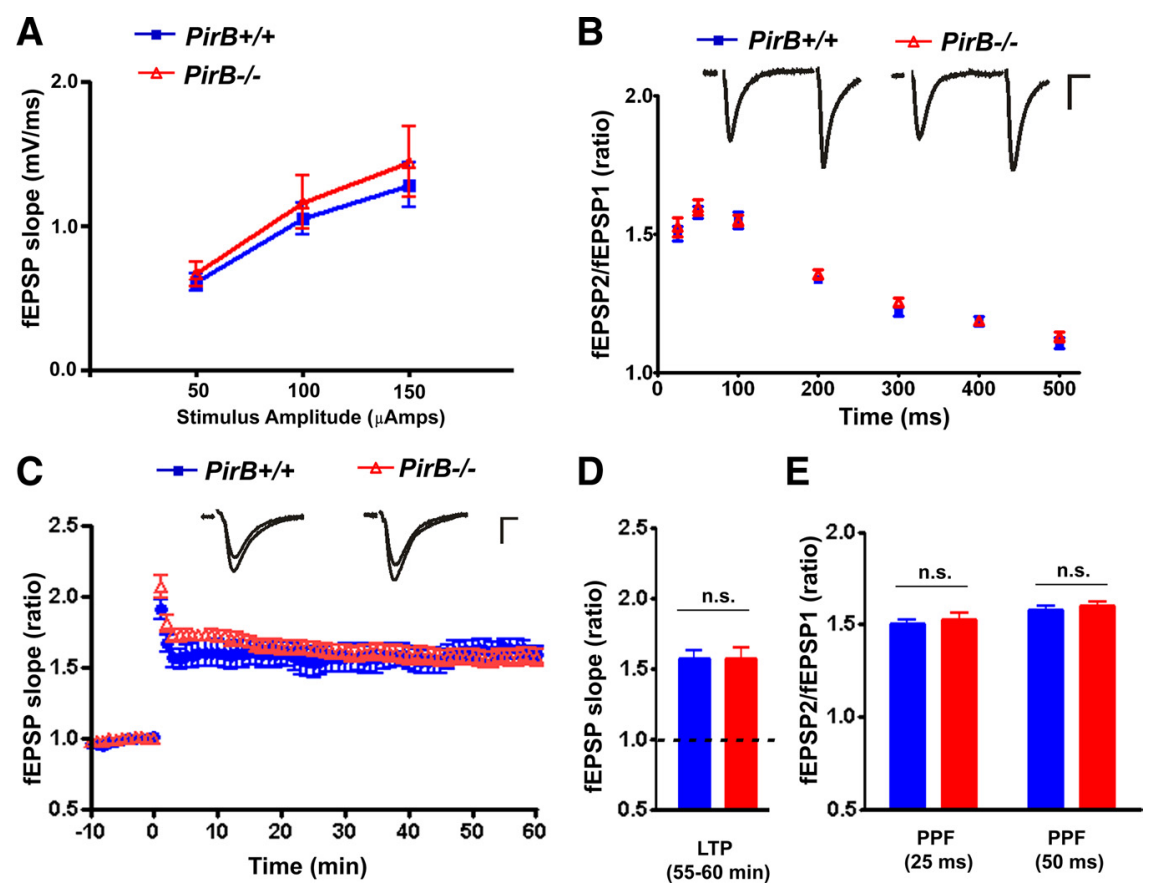

Figure 5. Genetic ablation of PirB does not result in altered LTP of synaptic transmission. $\boldsymbol{A}, \mathrm{I} / 0$ curves for basal synaptic transmission revealed no differences in fEPSP amplitudes between wild-type (PirB ${ }^{+/+}$; blue squares) and mutant (PirB ${ }^{-/-}$; red triangles) hippocampal slices. $B$, PPF in Pir $^{+/+}$and PirB ${ }^{-1-}$ slices. The increase in the second fEPSP amplitude over the first fEPSP amplitude was calculated, and the mean values were plotted against different interpulse intervals (25-500 ms). No significant difference was observed at any of the interpulse intervals. Insets show traces collected from experiments with an interpulse interval of $50 \mathrm{~ms}$. Calibration is $0.5 \mathrm{mV}, 5 \mathrm{~ms}$. C, Summary of LTP recordings after HFS stimulation ( $t=0 \mathrm{~min}$ ) of acute hippocampal slices of 6- to 8-week-old PirB ${ }^{+/+}$(blue squares) and PirB ${ }^{-1-}$ (red triangles) mice. D, Quantification of mean fEPSP at 55-66 min after HFS. LTP is not enhanced in PirB ${ }^{-1-}$ mice (blue; mean fEPSP $157 \pm 6 \%$ of baseline, $n=14$ slices $/ 6$ animals) compared with PirB $^{+/+}$mice (red; mean fEPSP $157 \pm 8 \%$ of baseline, $n=7$ slices/4 animals). Baseline is marked by dotted line. $E$, Quantification of PPF ratios at 25 and $50 \mathrm{~ms}_{\text {in PirB }}{ }^{+/+}$(blue) or PirB ${ }^{-1-}$ (red) slices. Statistical analysis was performed using Student's $t$ test. n.s. indicates not significantly different $(p>0.05)$. All error bars are SEMs.

\section{Loss of PirB attenuates OMgp-mediated inhibition of LTP}

In vitro, NgR1 and PirB collaborate to signal neurite outgrowth inhibition. Genetic ablation of PirB or bath application of antiPirB partially attenuates myelin inhibition of primary neurons. The combined ablation of PirB and NgR1 virtually abolishes neurite outgrowth inhibition in the presence of crude CNS myelin (Atwal et al., 2008). Furthermore, growth cone collapse assays revealed that PirB and NgR1 function as codependent receptors to signal acute responses to myelin inhibitors. Loss of either receptor alone is sufficient to significantly attenuate myelin inhibitorelicited growth cone collapse (Chivatakarn et al., 2007; Atwal et al., 2008). To examine whether PirB participates in myelin inhibitormediated suppression of activity-dependent synaptic plasticity, we used acute hippocampal slices from 6- to 8-week-old PirB mutants. As described above, recombinant OMgp was loaded into the recording electrode and locally applied to the dendritic field of CA1 neurons. LTP was induced by two HFS $(100 \mathrm{~Hz} ; 1$ s; separated by a 10-s interval). Although there was a trend toward decreased LTP in $\mathrm{PirB}^{-1-}$ slices acutely treated with OMgp (fEPSP: $142 \pm 3 \%$ ), it did not reach statistical significance $(p=0.07)$ compared with LTP recorded from PirB $^{-1-}$ slices in the absence of OMgp (fEPSP: $157 \pm$ $6 \%$ ) (Fig. 6A,B). Moreover, a direct comparison between the mean fEPSPs at 55-60 min after HFS of $\mathrm{NgR}^{-1-}(159 \pm 10 \%)$ and $\mathrm{PirB}^{-1-}(142 \pm 3 \%)$ slices treated with OMgp did not reveal a significant difference in LTP between these two mutants $(p=0.10)$. Collectively, our data show that loss of $N g R 1$ largely abrogates the inhibitory effects of OMgp on synaptic strength, whereas loss of PirB leads only to a partial release of the OMgp inhibitory effects on activity-dependent synaptic strength.

$N g R 1^{-/-}$, but not $\mathrm{PirB}^{-/-}$, mice show a hippocampal LTD phenotype

Because our previous studies showed that $N g R 1$ is necessary for the induction of NMDAR-dependent LTD at CA3CA1 synapses (H. Lee et al., 2008) and functional depletion of MHC1 molecules (a class of PirB ligands) impairs LTD (Huh et al., 2000), we wondered whether PirB plays a role in hippocampal LTD.

As shown by H. Lee et al., 2008, in acute hippocampal slices obtained from juvenile (P15-P17) NgR1 ${ }^{-1-}$ pups, LFS (900 paired pulses delivered at $1 \mathrm{~Hz}$ ) fails to induce LTD (fEPSP: $94 \pm 4 \%$ ). An identical stimulation protocol induced a significant decrease $(p<0.05)$ in the mean fEPSP in wild-type (fEPSP: $83 \pm$ $3 \%)$ and PirB $^{-1-}$ (fEPSP: $79 \pm 10 \%$ ) slices, resulting in robust LTD (Fig. 6C,D). LTD at CA3-CA1 synapses in PirB mutant mice at 55 min after induction is indistinguishable from LTD recordings of age-matched wild-type controls (Fig. $6 D)$. These results suggest that with respect to LTD the functions of $N g R 1$ and PirB in synaptic plasticity can be dissociated. Furthermore, we conclude that loss of PirB does not phenocopy the hippocampal LTP or LTD defects reported previously for mice with greatly reduced cell surface expression of MHC1 molecules (Huh et al., 2000).

Because NgR1 and PirB functionally collaborate in neurite outgrowth inhibition in vitro, we examined whether the combined loss of $N g R 1$ and PirB leads to enhanced LTP reminiscent of $\beta 2 \mathrm{~m} / \mathrm{TAP} 1$ or $\mathrm{CD} 3 \zeta$ mice (Huh et al., 2000). $\mathrm{NgR}^{-1-}$; $\mathrm{PirB}^{-1-}$ double mutant mice are viable into adulthood and indistinguishable at the gross anatomical level from wild-type littermate controls (Fig. 6E,F). LTP induced at CA3-CA1 synapses in acute slices of $\mathrm{NgR}^{-1-}$;PirB ${ }^{-/-}$double mutants (fEPSP: $156 \pm$ $5 \%$ ) is indistinguishable from that of age-matched wild-type controls (fEPSP: $162 \pm 14 \%$ ). Collectively, these studies show that loss of $\mathrm{NgR} 1$ or PirB alone or the combined loss of both receptors does not lead to altered LTP at CA1-CA3 synapses.

\section{Loss of $\mathrm{NgR} 1$ does not alter glutamate receptor subunit expression in vivo}

To begin to address how NgR1 influences activity-dependent synaptic strength, we examined the synaptic distribution of Nogo receptor components and different subunits of the NMDA- and AMPA-type glutamate receptors. Synaptosomes were isolated from neocortical and hippocampal homogenates of 3-, 6-, or 7-week-old NgR1 wild-type and mutant mice and further separated into extrasynaptic, synaptic junction, presynaptic, and postsynaptic density fractions (Fig. 7).

Analysis of wild-type mouse fractions revealed that $\mathrm{NgR} 1$ is enriched postsynaptically. Antibody specificity was verified by lack of anti-NgR1 labeling in any of the synaptic fractions isolated 
from $N g R 1$ mutant pups (Fig. 7A). The NgR1 coreceptors Lingo-1 and p75 are present in hippocampal homogenates (T. H. Lee et al., 1998; Roux et al., 1999; H. Lee et al., 2008). Lingo-1 is heavily enriched in presynaptic fractions; $\mathrm{p} 75$, expressed by septo-hippocampal cholinergic fibers (Sugaya et al., 1998), is present in homogenates of $\mathrm{NgR1}^{+/+}$and $\mathrm{NgR1}^{-/-}$mice but below detection levels in presynaptic or postsynaptic density fractions (Fig. 7A). Consistent with the observation that loss of $\mathrm{NgR} 1$ does not alter Nogo-A protein expression in brain (Zheng et al., 2005), Nogo-A in hippocampal homogenates and synaptic fractions of $\mathrm{NgR}^{+/+}$and $\mathrm{NgR1}^{-/-}$mice are very similar (Fig. $7 A$ ).

We showed previously that FGF2 enhances activity-dependent strength of synaptic transmission in $N g R 1$ mutant mice. The enhancing effects of FGF2 on LTP in $\mathrm{NgR}^{-1-}$ mice are FGFR-kinase dependent (H. Lee et al., 2008). Analysis of FGFR1 expression levels revealed that loss of $\mathrm{NgR} 1$ does not result in altered expression or distribution of FGFR1 and its downstream effector FRS2 $\alpha$ (Fig. 7A).

NMDARs are tetramers composed of two obligatory NR1 subunits and two regulatory subunits, usually a combination of NR2A and NR2B. Calcium influx through NMDARs is determined by their subunit distribution. The relative abundance and distribution of NR1 and NR2B in synaptic density fraction is very similar between $\mathrm{NgR1}^{+/+}$and $\mathrm{NgR1}^{-1-}$ mice, suggesting that loss of NgR1 does not alter the NR1/ NR2B ratio. Repetitive activation of NMDAR leads to insertion of AMPA receptors in the postsynaptic membrane. Loss of $\mathrm{NgRl}^{-1-}$ does not alter expression levels of the AMPAR subunit GluR1 or CaMKII $\alpha$ (Fig. 7A). To confirm the quality of our biochemical preparations, synaptic fractions were analyzed for the presence of several marker proteins, including synaptophysin (extrasynaptic fraction), syntaxin 1A (presynaptic), and PSD-95 (postsynaptic). Together, these results reveal that loss of $N g R 1$ does not affect expression and distribution of various components of the NgR1 receptor complex in vivo. Furthermore, distribution of several subunits of the NMDA- and AMPA-type glutamate receptors and downstream effectors implicated in synaptic plasticity appears not to be altered.

\section{Activation of the mitogen-activated protein kinase ERK1/2 is increased in $\mathrm{NgR1}$ mutants}

Because no apparent changes in protein expression levels or synaptic distribution were detected between $\mathrm{NgR}^{+/+}$and $\mathrm{NgR}^{-/-}$ mice, we next asked whether the activation level of hippocampal or cortical signaling intermediates was altered between the two genotypes. Although protein levels may remain unchanged,
PirB-/-
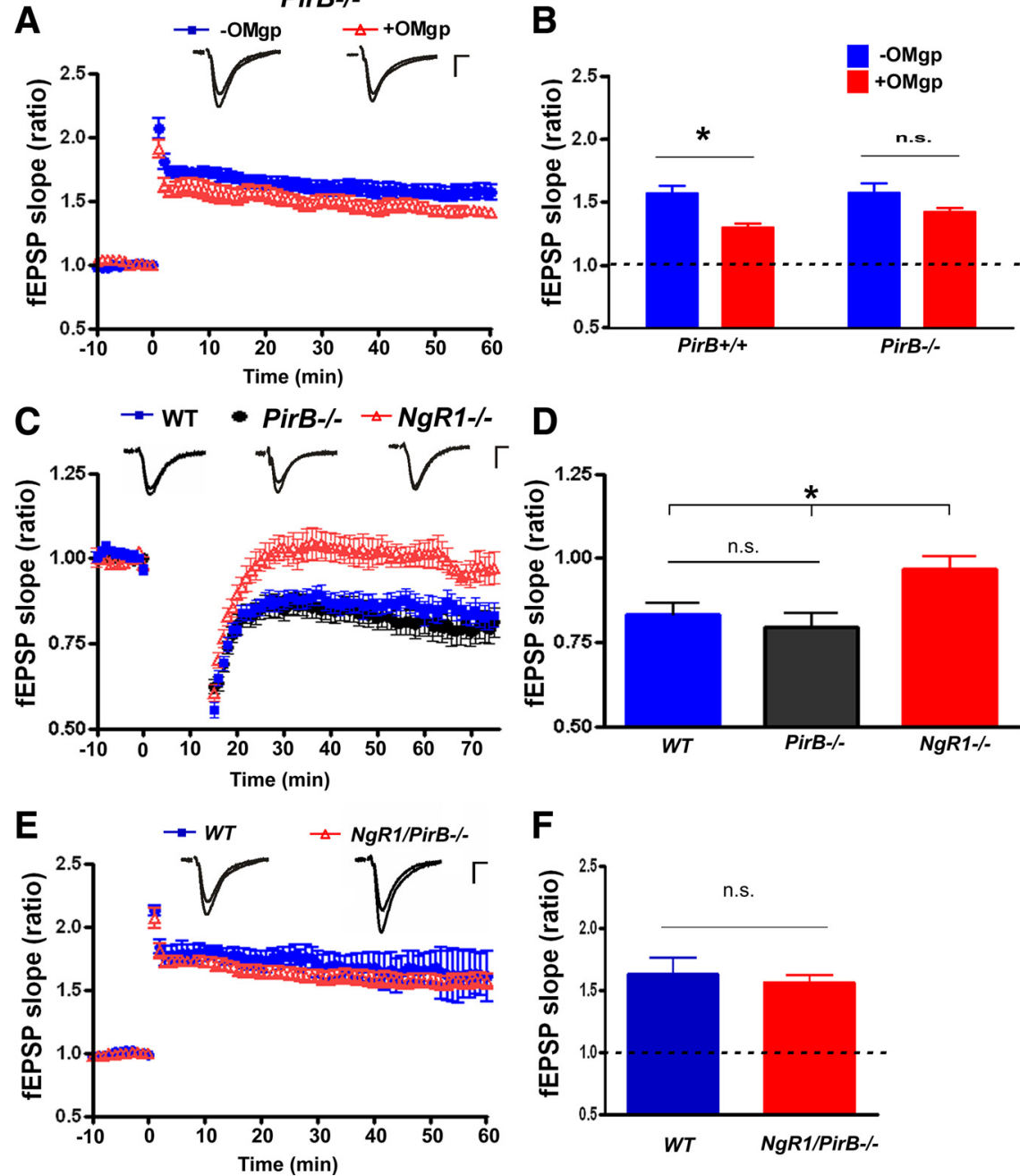

Figure 6. Loss of PirB attenuates OMgp-mediated suppression of LTP. A, Summary of LTP recordings after HFS ( $t=0 \mathrm{~min}$ ) of acute hippocampal slices of 6- to 8-week-old PirB ${ }^{-1-}$ mice in the absence (blue squares) or presence (red triangles) of acutely applied OMgp. Representative traces before and after HFS are shown as Insets. Calibration is $0.5 \mathrm{mV}, 5 \mathrm{~ms}$. B, Quantification of mean fEPSPs 55-60 min after HFS from PirB ${ }^{-1-}$ slices with OMgp (red; mean fEPSP $142 \pm 3 \%$ of baseline, $n=9$ slices/4 animals) is not significantly decreased compared with control PirB ${ }^{-1-}$ (no 0Mgp) slices (blue; mean fEPSP $157 \pm 8 \%$ of baseline, $n=14$ slices/6 animals). OMgp-treated PirB ${ }^{-1-}$ slices showed a trend toward decreased LTP that did not reach statistical significance ( $p=0.07$ ). C, Summary of LTD experiments in acute wild-type (WT), PirB ${ }^{-1-}$, and $N g R 1^{-1-}$ hippocampal slices. The same LFS protocol ( 900 pulses at $1 \mathrm{hz}$ ) that failed to induce LTD in $\mathrm{NgR}^{-1-}$ slices (red triangles) induced robust and stable LTD in WT (black dots) and PirB ${ }^{-1-}$ (blue squares) slices. Insets show traces collected before and after LFS. Calibration is $0.5 \mathrm{mV}, 5 \mathrm{~ms}$. D, Quantification of mean fEPSP data shown in Cin WT (blue; fEPSP $83 \pm 3 \%, n=9$ slices $/ 4$ animals), PirB ${ }^{-1-}$ (black; fEPSP $79 \pm$ $10 \%, n=9$ slices $/ 4$ animals), and $N g R 1^{-1-}$ (red; fEPSP $94 \pm 4 \%$ of baseline, $n=7$ slices $/ 3$ animals) slices at $55-60$ min after S.E, Summary of LTP recordings after HFS ( $t=0 \mathrm{~min}$ ) of wild-type (WT; blue squares) and $\mathrm{NgR}^{-1-}$; PirB ${ }^{-1-}$ double null (red triangles) hippocampal slices. Representative traces before and after HFS are shown as Insets. Calibration is $0.5 \mathrm{mV}, 5 \mathrm{~ms}$. $\boldsymbol{F}$, Quantification of mean fEPSP data in $E$ in WT (blue; fEPSP $162 \pm 14 \%, n=5$ slices $/ 3$ animals) and $N g R 1^{-1-}$;PirB ${ }^{-1-}$ (red; fEPSP $156 \pm 5 \%, n=4$ slices/2 animals) slices at $55-60$ min after LFS revealed no significant difference. Statistical analysis was performed using Student's t test. $*$ indicates significance, $p<0.05$. n.s. indicates not significantly different. All error bars are SEMs.

many proteins localized to synapses are activated or regulated by phosphorylation of upstream kinases (Lisman, 2003; Sweatt, 2004).

ERK1/2 have previously been shown to regulate activitydependent synaptic strength in the hippocampus (Sweatt, 2004; Thomas and Huganir, 2004) and visual cortex during OD plasticity (Di Cristo et al., 2001; Takamura et al., 2007). To examine the level of $\mathrm{p}-\mathrm{ERK} 1 / 2$ in $\mathrm{NgR} 1^{-1-}$ mice, we probed synaptic fractions with a p-ERK1/2-specific antibody. As shown in Figure 7, increased levels of p-ERK were detected in synaptic density fractions derived from $\mathrm{NgR}^{-l-}$ neocortex (Fig. $7 \mathrm{~B}, \mathrm{C}$ ) or hip- 

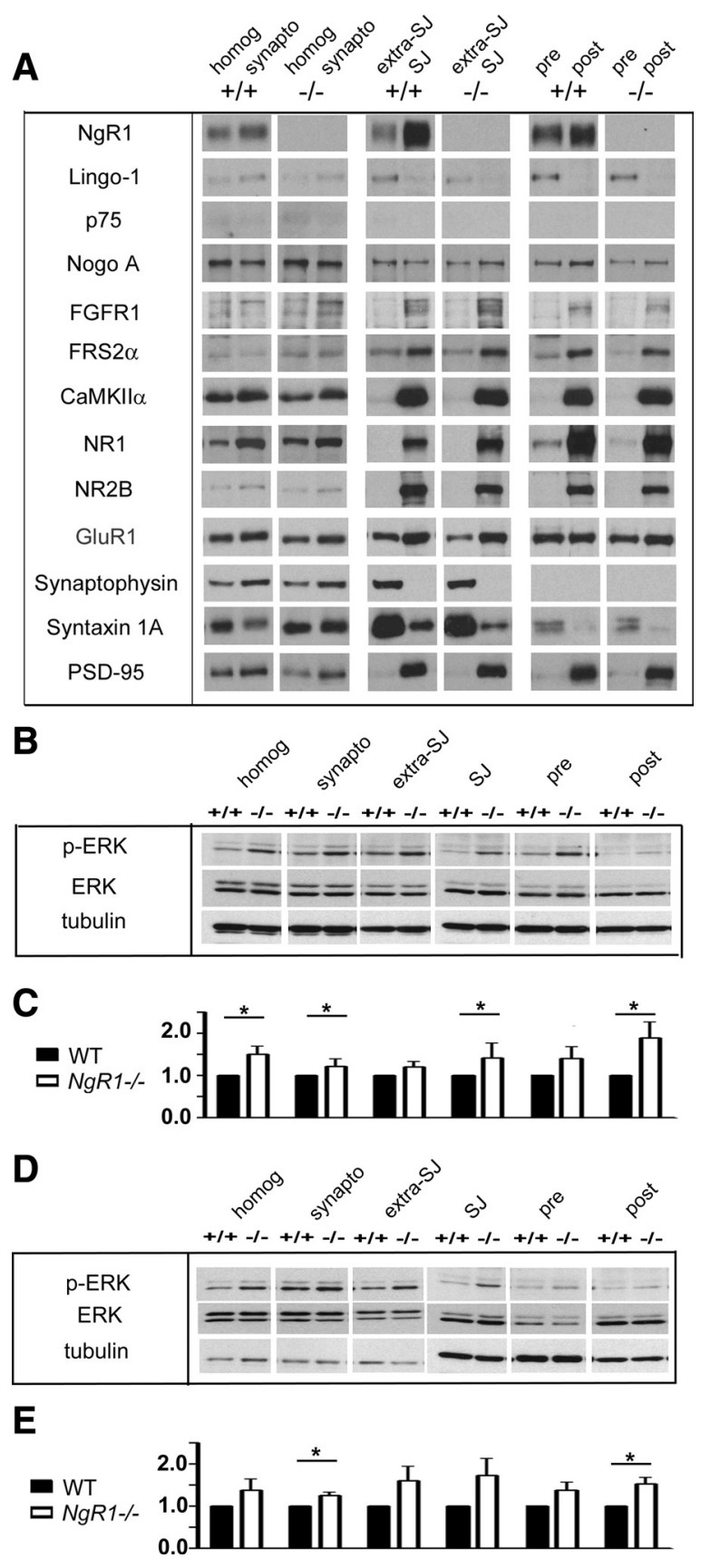

Figure 7. Loss of $\mathrm{NgR} 1$ leads to increased phosphorylation of ERK. $A$, Synaptic density fractions were isolated from adult hippocampus of $\mathrm{NgR} 1$ wild-type $(+/+)$ and age-matched mutants $(-/-)$ and subjected to Western blot analysis using antibodies specific for components of the Nogo receptor complex (NgR1, Lingo-1, p75, and Nogo-A), the FGFR1 receptor and the FGFR docking protein FRS $2 \alpha$, calcium-sensitive kinase CamKII $\alpha$, and the NMDA and AMPA receptor components NR1, NR2B, and GluR1. For $\mathrm{NgR}^{+/+}$and $\mathrm{NgR1^{-1- }}$ fractions, equal amounts of total protein were loaded for hippocampal homogenate (homog), synaptosomes (synapto), extrasynaptic junction (extra SJ), synaptic junction (SJ), presynaptic density fraction (pre), and postsynaptic density fraction (post). To ensure the quality of the biochemical separation of different synaptic fractions, antibodies specific for the synaptic marker proteins synaptophysin (extra-SJ), syntaxin 1A (presynaptic), and PSD-95 (postsynaptic) were used. $\boldsymbol{B}, \boldsymbol{D}$, Immunobloting of synaptosomal density fractions isolated from adult mouse neocortex $(\boldsymbol{B})$ and hippocampus $(\boldsymbol{D})$ of $\mathrm{NgR1}$ wild-type $(+/+)$ and $\mathrm{NgR1}$ mutant $(-/-)$ mice probed with antibodies specific for $p$-ERK, total ERK1/2 (ERK), and class III $\beta$-tubulin. Elevated levels of $p$-ERK are found in most synaptic fractions of $N g R 1^{-1-}$ mice compared with wild-type controls. C, E, Quantification of p-ERK2 immunoreactivity (lower band) on Western blots shown in $\boldsymbol{B}$ and $\boldsymbol{D}$ revealed a significant increase in the homogenate, synaptosomes, synaptic junction, and postsynaptic density fractions in the neocortex of $\mathrm{NgR1^{-/- }}$ compared with $\mathrm{NgR}^{+/+}(\mathbf{C})$. In the hippocampus synaptosomes and postsynaptic density fractions showed a significant increase of $p$-ERK2 of

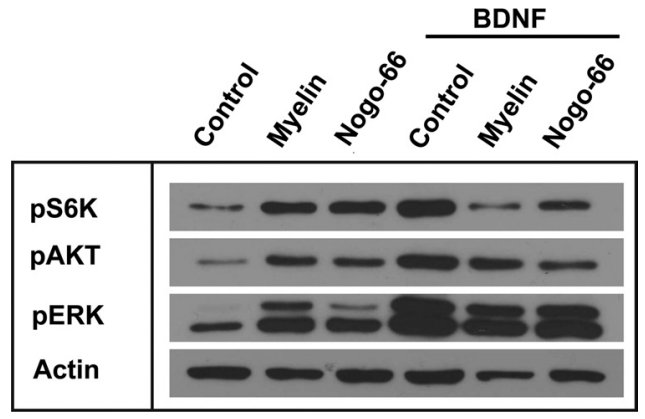

Figure 8. CNS myelin and Nogo-66 attenuate BDNF signaling in primary neurons. DIV9 primary cortical neurons were treated with vehicle (control), crude CNS myelin (myelin), or AP-Nogo66 (Nogo-66) for 30 min (lanes 1, 2, and 3). In lanes 4, 5, and 6 neurons were pretreated for 30 min with vehicle, myelin, or Nogo-66 and then incubated for an additional 30 min with BDNF before lysis and immunoblotting. Membranes were probed with antibodies specific for phosphorylated p70S6 kinase (pS6K), pAKT, and pERK1/2. Anti-actin is shown as a loading control. Representative blots of a total $n=3$ for each antibody are shown.

pocampus (Fig. $7 D, E$ ) compared with littermate wild-type control fractions. Significantly increased levels of p-ERK were seen in several synaptic fractions of $N g R 1$ mutants compared with the wild-type mice (6-7 weeks old), including synaptosomes, synaptic junction, and postsynaptic density fraction in the neocortex (Fig. 7C) and synaptosomes and postsynaptic density fraction of the hippocampus (Fig. 7E). As was the case for synaptosomes isolated from adult mice, p-ERK in 3-week-old $\mathrm{NgR1}^{-/-}$mutant fractions was elevated compared with $\mathrm{NgR}^{+/+}$ controls (data not shown). Together, our findings suggest that ERK signaling is constitutively elevated in the neocortex and hippocampus of $\mathrm{NgR} 1$ mutants.

\section{AKT and p70S6-kinase signaling is negatively regulated by crude myelin and Nogo}

To examine whether acute treatment of primary neurons with myelin inhibitors leads to altered regulation of signaling pathways previously implicated in neuronal growth and synaptic plasticity, primary cortical neurons (DIV9) were treated with crude CNS myelin or Nogo-66. After an initial increase in p-ERK1/2, prolonged treatment with crude myelin leads to a decrease in p-ERK1/2 (data not shown). As a positive control for ERK1/2 activation, neurons were incubated with BDNF. Interestingly, myelin pretreatment of primary neurons attenuates BDNFelicited activation of ERK1/2 (Fig. 8). In addition, myelin attenuated BDNF-elicited activation (phosphorylation at Ser473) of AKT and p70S6-kinase (Thr389). This suggests that crude CNS myelin contains factors that attenuate BDNF signaling in primary neurons. Studies with recombinant AP-Nogo-66 showed that, reminiscent of the action of crude CNS myelin, Nogo-66 attenuates BDNF-elicited activation of AKT, p70S6K, and ERK1/2 (Fig. 8 ). Because BDNF has previously been shown to promote regenerative neuronal growth and sprouting (Zhou and Shine, 2003; Blesch and Tuszynski, 2007; Kwon et al., 2007) and also plays a key role in activity-dependent regulation of synaptic strength (Korte et al., 1995; Rex et al., 2007; Lu et al., 2008), our data suggest that the inhibitory effects of Nogo-66 on synaptic plasticity may at least in part be a reflection of reduced BDNF signaling.

\section{$\leftarrow$}

$N g R 1^{-1-}$ mice compared with the corresponding fractions of $\mathrm{NgRT}^{+/+}$mice. ${ }^{*} p<0.05$ statistically significant, Student's $t$ test of densitometrically scanned blots from three independent experiments. 
Coupled with our previous observation that neuronal NgR1 attenuates FGF2 signaling (H. Lee et al., 2008), the present findings suggest that myelin inhibitors antagonize signaling cascades activated by growth factors.

\section{Discussion}

Here, we report on the identification of Nogo and OMgp as novel regulators of activity-driven synaptic plasticity. In the hippocampus, acute Nogo-66 and OMgp suppress LTP at Schaffer collateral-CA1 synapses, but have no apparent effects on basal synaptic transmission or presynaptic neurotransmitter release. Mechanistic studies revealed that $N g R 1$ and $\operatorname{PirB}$, but not $p 75$, are important for ligand-dependent inhibition of LTP. In vivo, functional ablation of $N g R 1$ increases ERK1/2 activation, a signaling intermediate implicated in neuronal growth, OD plasticity, activitydriven synaptic strength, learning, and memory. In primary neurons, Nogo attenuates BDNF-elicited activation of ERK1/2, $\mathrm{AKT}$, and p70S6 kinase. The emerging antagonistic relation between growth factor signaling and myelin inhibitor expression and function suggests a coordinated and highly regulated interaction between these two classes of molecules. The identification of Nogo, OMgp, and their high-affinity receptors NgR1 and PirB as negative regulators of activity-dependent synaptic plasticity suggests novel roles for these molecules beyond their known function in growth inhibition and regulation of neuronal morphology.

\section{Myelin inhibitors regulate synaptic plasticity}

Nogo-A, OMgp, and NgR1 are expressed in the juvenile and adult hippocampus and are abundantly found in presynaptic and postsynaptic density fractions. Loss of $\mathrm{NgR} 1$, but not PirB, impairs LTD at CA3-CA1 synapses. Loss of $N g R 1$, PirB, or both receptors has no apparent effect on NMDAR-dependent LTP in CA1 neurons. Acute application of Nogo-66 or OMgp to CA3CA1 synapses attenuates LTP, and the inhibitory effects are no longer observed in $\mathrm{NgR}^{-/-}$mice and are reduced in $\mathrm{PirB}{ }^{-/-}$ mice. PPF experiments suggest that Nogo-66 and OMgp decrease LTP via a postsynaptic mechanism. Consistent with this idea, the $N g R 1$ promoter is highly active in CA1 but not CA3 neurons. Collectively, our studies provide evidence that $N g R 1$ regulates functional synaptic plasticity in the hippocampus. Because NgR1 expression itself is regulated by neuronal activity (Josephson et al., 2001) and has been shown to regulate the shape of dendritic spines (H. Lee et al., 2008) NgR1 is well suited to link electrical activity to structural changes in mature CNS neurons.

In line with the Allen Brain Atlas (http://www.brain-map. org), we found low to moderate expression of $\operatorname{PirB}$ in principal neurons of the adult mouse hippocampus. Loss of MHC1 surface expression ( $\beta 2 \mathrm{~m} / \mathrm{TAP} 1$ mutants) results in enhanced LTP and absence of LTD at Schaffer collateral-CA1 synapses (Huh et al., 2000). Loss of $C D 3 \zeta$, a signaling component of the T cell receptor also expressed in the adult hippocampus, phenocopies the LTP and LTD defects of $\beta 2 \mathrm{~m} /$ TAP1-deficient mice (Huh et al., 2000). Because other $\mathrm{T}$ cell receptor components appear not to be expressed in the adult hippocampus (Syken and Shatz, 2003), and $\mathrm{CD} 3 \zeta$ does not directly interact with $\mathrm{MHC} 1 \mathrm{~s}$, we examined whether, like MHC1s, PirB participates in CA3-CA1 synaptic plasticity. LTP and LTD in PirB mutants is robust and indistinguishable from age-matched wild-type controls. This suggests that PirB is not necessary for the induction or expression of LTP or LTD in CA1 neurons. Based on these observations we conclude that $\mathrm{MHC1}$-mediated regulation of synaptic plasticity in CA1 neurons is independent of PirB.

\section{Cross talk between myelin inhibitor and growth factor signaling pathways}

Expression of components of the Nogo/NgR1 system is downregulated by neural activity or exercise (Josephson et al., 2003; Griesbach et al., 2009). Conversely, BDNF (Vaynman and Gomez-Pinilla, 2005) and FGF2 (Gomez-Pinilla et al., 1997) are up-regulated by increased neural activity or exercise. Furthermore, there is evidence for an inverse regulation of myelin inhibitor and growth factor signaling: (i) BDNF antagonizes injury induced up-regulation of Nogo-A in the hippocampus (Chytrova et al., 2008), (ii) preincubation with BDNF renders primary neurons largely resistant to myelin inhibitors (Gao et al., 2003), and (iii) $N g R 1$ functions as an antagonist of FGF2 (H. Lee et al., 2008).

Here, we expand on those observations and show that Nogo preincubation attenuates BDNF signaling in primary neurons. In the presence of CNS myelin or Nogo-66, BDNF elicited activation of MAP kinase signaling (as assessed by p-ERK1/2) and the phosphatidylinositol 3-kinase (PI3K)-AKT-mTOR-p70S6K pathway (as assessed by p-AKT and p-p70S6K) is decreased. These findings are further corroborated by elevated phosphorylation of ERK1/2 in neocortical and hippocampal extracts of $N g R 1^{-1-}$ mice. Tetanic stimulation results in the secretion of BDNF (Balkowiec and Katz, 2002), and BDNF is important for induction and expression of LTP (Lu et al., 2008). ERK1/2 have been implicated in hippocampal LTP and learning (English and Sweatt, 1997; Kelleher et al., 2004). Recent evidence shows that ERK1/2 participate in synaptic activation of mTOR-p70S6K signaling in LTP (Tsokas et al., 2005, 2007). The canonical pathway for $\mathrm{mTOR}$ regulation is independent of ERK1/2 and involves PI3K-PDK1-Akt-dependent inactivation of the mTOR suppressor TSC2 (Manning et al., 2002; Potter et al., 2002), which then leads to mTOR-p70S6K dependent translation of mRNAs and de novo protein synthesis at active synapses (Hoeffer and Klann, 2010). It has been proposed that mTOR-mediated protein synthesis in LTP is regulated by coincident activity of the PI3K and ERK1/2 signaling cascades (Tsokas et al., 2007). In vitro, Nogo-66 attenuated BDNF-elicited activation of both the AKT-p70S6K and ERK1/2 pathways. We propose that Nogo/NgR1 signaling suppresses BDNF action and thereby attenuates LTP.

Conversely, the failure of CA1 neurons to express LTD in NgR1 mutants may be a result of elevated AKT-mTOR-p70S6K activity. Previous studies found that PI3K signaling regulates hippocampal LTD (Daw et al., 2002). In $P T E N^{+/-}$mice, for example, LTD in CA1 neurons is absent but can be restored by pharmacological inhibition of PI3K (Wang et al., 2006). In primary neurons, Nogo-66 reduces AKT and p70S6K activity in the presence of BDNF. If loss of $N g R 1$ results in elevated AKT activity at CA1 synapses, this may impair LTD. Although our data suggest a coupling of myelin inhibitor signaling to regulation of synaptic protein translation, additional studies are needed to test this model more directly. One prediction is that inhibition of PI3K in $N g R 1^{-/-}$slices is sufficient to rescue the observed LTD defect.

\section{Implications for OD plasticity}

Genetic ablation of Nogo-A/B or NgR1 leads to an extension of the CP (McGee et al., 2005). PirB-TM mice show enhanced OD plasticity during and after the $\mathrm{CP}$, as assessed by Arc expression in the binocular zone of V1 (Syken et al., 2006). This suggests that in the healthy brain physiological signaling by these two receptor systems is important for consolidating neuronal connectivity.

Multiple lines of evidence indicate that intracortical inhibition is an important gatekeeper for onset and closure of the CP. Reducing GABA function by genetic ablation of the GABA- 
synthetic enzyme GAD65 or dark-rearing delays CP onset (Hensch et al., 1998). Conversely, enhanced maturation of GABAergic interneurons or local infusion of benzodiazepines increases intracortical inhibition and expedites onset and closure of the CP (Huang et al., 1999; Hensch and Stryker, 2004). In adulthood, pharmacological reduction of intracortical GABA function restores OD plasticity (Maya Vetencourt et al., 2008; Harauzov et al., 2010) and reduced intracortical GABAergic inhibition leads to enhanced LTP-like synaptic plasticity in layer IV of V1 after HFS (Harauzov et al., 2010). Together, these findings argue that modulation of synaptic inhibition in V1 directly affects OD plasticity in response to monocular deprivation. When coupled with our observation that Nogo, OMgp, NgR1, and PirB reduce activity-driven synaptic transmission in the hippocampus, the same molecules may increase the inhibitory tonus in V1 and thereby restrict experience-dependent neuronal plasticity. Thus, myelin inhibitors and their receptors may contribute to the "excitatory-inhibitory balance" in the visual cortex in early postnatal life and more generally influence synaptic homeostasis in different brain regions throughout adulthood.

\section{Implications for CNS regeneration}

Remarkably, the spectrum of extracellular cues that limits OD plasticity at the end of the CP overlaps heavily with the molecular players implicated in restricting neuronal growth and sprouting after injury to the adult mammalian CNS. Beyond the CP, OD plasticity in favor of the nondeprived eye is enhanced by functional ablation of chondroitin sulfate proteogycans (CSPGs) (Pizzorusso et al., 2002), loss of Nogo- $A / B$ or the Nogo receptors NgR1 and PirB (McGee et al., 2005; Syken et al., 2006). In addition to extracellular growth inhibitors, the state of neuronal activity is a critical gatekeeper of OD plasticity. Lowering the inhibitory tonus in the adult visual cortex "reopens" a window of enhanced OD plasticity (Hensch, 2005).

After injury to the adult mammalian CNS, CSPGs and myelin inhibitors limit reactive neuronal sprouting. Injury-induced neuronal sprouting and structural plasticity is enhanced by antagonism of extracellular growth inhibitors (Bradbury et al., 2002; Cafferty et al., 2010; Hoeffer and Klann, 2010; J. K. Lee et al., 2010), elevated neurotrophins (Blesch and Tuszynski, 2009), activation of intrinsic growth programs (Romero et al., 2007; Park et al., 2008), or combinations thereof. Experimentally enhanced neural plasticity often correlates with improved functional outcomes. When combined with task-specific rehabilitative training, performance in trained animals is further improved compared with injured nontrained animals (Girgis et al., 2007; Maier et al., 2008; Garcia-Alias et al., 2009). Thus, like OD plasticity in favor of the nondeprived eye, prolonged neuronal activity appears to beneficially influence the degree of plasticity and functional recovery after injury to the adult mammalian CNS. Injury-induced adaptation of a neural network (spontaneous or enhanced by experimental treatments) leads to substantial reorganization of neuronal structure at multiple levels. At the same time, injury also causes a range of functional synaptic changes. We propose that antagonism of myelin inhibitors, including Nogo and OMgp, may not only lower the growth inhibitory milieu of adult CNS tissue but simultaneously lower the inhibitory tonus in neuronal networks. As a result, increased neuronal activity and synaptic transmission may enable activity-driven reorganization and refinement of injured neural networks that result in improved behavioral outcomes.

Collectively, our studies identify Nogo, OMgp, and their highaffinity receptors as negative regulators of activity-driven synap- tic strength and thus contribute to our understanding of the role of these molecules in neural health, injury, and disease.

\section{References}

Atwal JK, Pinkston-Gosse J, Syken J, Stawicki S, Wu Y, Shatz C, TessierLavigne M (2008) PirB is a functional receptor for myelin inhibitors of axonal regeneration. Science 322:967-970.

Balkowiec A, Katz DM (2002) Cellular mechanisms regulating activitydependent release of native brain-derived neurotrophic factor from hippocampal neurons. J Neurosci 22:10399-10407.

Bareyre FM, Kerschensteiner M, Raineteau O, Mettenleiter TC, Weinmann O, Schwab ME (2004) The injured spinal cord spontaneously forms a new intraspinal circuit in adult rats. Nat Neurosci 7:269-277.

Barrett GL, Greferath U, Barker PA, Trieu J, Bennie A (2005) Co-expression of the P75 neurotrophin receptor and neurotrophin receptor-interacting melanoma antigen homolog in the mature rat brain. Neuroscience 133:381-392.

Barrette B, Vallières N, Dubé M, Lacroix S (2007) Expression profile of receptors for myelin-associated inhibitors of axonal regeneration in the intact and injured mouse central nervous system. Mol Cell Neurosci 34:519-538.

Blesch A, Tuszynski MH (2007) Transient growth factor delivery sustains regenerated axons after spinal cord injury. J Neurosci 27:10535-10545.

Blesch A, Tuszynski MH (2009) Spinal cord injury: plasticity, regeneration and the challenge of translational drug development. Trends Neurosci 32:41-47

Bliss TV, Collingridge GL (1993) A synaptic model of memory: long-term potentiation in the hippocampus. Nature 361:31-39.

Boulanger LM (2009) Immune proteins in brain development and synaptic plasticity. Neuron 64:93-109.

Bradbury EJ, Moon LD, Popat RJ, King VR, Bennett GS, Patel PN, Fawcett JW, McMahon SB (2002) Chondroitinase ABC promotes functional recovery after spinal cord injury. Nature 416:636-640.

Cafferty WB, Duffy P, Huebner E, Strittmatter SM (2010) MAG and OMgp synergize with Nogo-A to restrict axonal growth and neurological recovery after spinal cord trauma. J Neurosci 30:6825-6837.

Chen Y, Stevens B, Chang J, Milbrandt J, Barres BA, Hell JW (2008) NS21: re-defined and modified supplement B27 for neuronal cultures. J Neurosci Methods 171:239-247.

Chivatakarn O, Kaneko S, He Z, Tessier-Lavigne M, Giger RJ (2007) The Nogo-66 receptor NgR1 is required only for the acute growth conecollapsing but not the chronic growth-inhibitory actions of myelin inhibitors. J Neurosci 27:7117-7124.

Chytrova G, Ying Z, Gomez-Pinilla F (2008) Exercise normalizes levels of MAG and Nogo-A growth inhibitors after brain trauma. Eur J Neurosci 27:1-11.

Corriveau RA, Huh GS, Shatz CJ (1998) Regulation of class I MHC gene expression in the developing and mature CNS by neural activity. Neuron 21:505-520.

Datwani A, McConnell MJ, Kanold PO, Micheva KD, Busse B, Shamloo M, Smith SJ, Shatz CJ (2009) Classical MHCI molecules regulate retinogeniculate refinement and limit ocular dominance plasticity. Neuron 64:463-470.

Daw MI, Bortolotto ZA, Saulle E, Zaman S, Collingridge GL, Isaac JT (2002) Phosphatidylinositol 3 kinase regulates synapse specificity of hippocampal long-term depression. Nat Neurosci 5:835-836.

Di Cristo G, Berardi N, Cancedda L, Pizzorusso T, Putignano E, Ratto GM, Maffei L (2001) Requirement of ERK activation for visual cortical plasticity. Science 292:2337-2340.

Dorfman JR, Zerrahn J, Coles MC, Raulet DH (1997) The basis for selftolerance of natural killer cells in beta2-microglobulin- and TAP-1- mice. J Immunol 159:5219-5225.

English JD, Sweatt JD (1997) A requirement for the mitogen-activated protein kinase cascade in hippocampal long term potentiation. J Biol Chem 272:19103-19106.

Florence SL, Taub HB, Kaas JH (1998) Large-scale sprouting of cortical connections after peripheral injury in adult macaque monkeys. Science 282:1117-1121

Gao Y, Nikulina E, Mellado W, Filbin MT (2003) Neurotrophins elevate cAMP to reach a threshold required to overcome inhibition by MAG through extracellular signal-regulated kinase-dependent inhibition of phosphodiesterase. J Neurosci 23:11770-11777. 
García-Alías G, Barkhuysen S, Buckle M, Fawcett JW (2009) Chondroitinase $\mathrm{ABC}$ treatment opens a window of opportunity for task-specific rehabilitation. Nat Neurosci 12:1145-1151.

Giger RJ, Wolfer DP, De Wit GM, Verhaagen J (1996) Anatomy of rat semaphorin III/collapsin-1 mRNA expression and relationship to developing nerve tracts during neuroembryogenesis. J Comp Neurol 375:378-392.

Gil V, Bichler Z, Lee JK, Seira O, Llorens F, Bribian A, Morales R, ClaverolTinture E, Soriano E, Sumoy L, Zheng B, Del Río JA (2010) Developmental expression of the oligodendrocyte myelin glycoprotein in the mouse telencephalon. Cereb Cortex 20:1769-1779.

Girgis J, Merrett D, Kirkland S, Metz GA, Verge V, Fouad K (2007) Reaching training in rats with spinal cord injury promotes plasticity and task specific recovery. Brain 130:2993-3003.

Gómez-Pinilla F, Dao L, So V (1997) Physical exercise induces FGF-2 and its mRNA in the hippocampus. Brain Res 764:1-8.

Griesbach GS, Hovda DA, Gomez-Pinilla F (2009) Exercise-induced improvement in cognitive performance after traumatic brain injury in rats is dependent on BDNF activation. Brain Res 1288:105-115.

Grünewald E, Kinnell HL, Porteous DJ, Thomson PA (2009) GPR50 interacts with neuronal NOGO-A and affects neurite outgrowth. Mol Cell Neurosci 42:363-371.

Harauzov A, Spolidoro M, DiCristo G, De Pasquale R, Cancedda L, Pizzorusso T, Viegi A, Berardi N, Maffei L (2010) Reducing intracortical inhibition in the adult visual cortex promotes ocular dominance plasticity. J Neurosci 30:361-371.

Hensch TK (2005) Critical period plasticity in local cortical circuits. Nat Rev Neurosci 6:877-888.

Hensch TK, Stryker MP (2004) Columnar architecture sculpted by GABA circuits in developing cat visual cortex. Science 303:1678-1681.

Hensch TK, Fagiolini M, Mataga N, Stryker MP, Baekkeskov S, Kash SF (1998) Local GABA circuit control of experience-dependent plasticity in developing visual cortex. Science 282:1504-1508.

Hoeffer CA, Klann E (2010) mTOR signaling: at the crossroads of plasticity, memory and disease. Trends Neurosci 33:67-75.

Holtmaat A, Svoboda K (2009) Experience-dependent structural synaptic plasticity in the mammalian brain. Nat Rev Neurosci 10:647-658.

Huang ZJ, Kirkwood A, Pizzorusso T, Porciatti V, Morales B, Bear MF, Maffei L, Tonegawa S (1999) BDNF regulates the maturation of inhibition and the critical period of plasticity in mouse visual cortex. Cell 98:739-755.

Huber AB, Weinmann O, Brösamle C, Oertle T, Schwab ME (2002) Patterns of Nogo mRNA and protein expression in the developing and adult rat and after CNS lesions. J Neurosci 22:3553-3567.

Huh GS, Boulanger LM, Du H, Riquelme PA, Brotz TM, Shatz CJ (2000) Functional requirement for class I MHC in CNS development and plasticity. Science 290:2155-2159.

Hunt D, Mason MR, Campbell G, Coffin R, Anderson PN (2002) Nogo receptor mRNA expression in intact and regenerating CNS neurons. Mol Cell Neurosci 20:537-552.

Josephson A, Widenfalk J, Widmer HW, Olson L, Spenger C (2001) NOGO mRNA expression in adult and fetal human and rat nervous tissue and in weight drop injury. Exp Neurol 169:319-328.

Josephson A, Trifunovski A, Schele C, Widenfalk J, Wahlestedt C, Bren S, Olson L, Spenger C (2003) Activity-induced and developmental downregulation of the Nogo receptor. Cell Tissue Res 311:333-342.

Karlén A, Karlsson TE, Mattsson A, Lundströmer K, Codeluppi S, Pham TM, Bäckman CM, Ogren SO, Aberg E, Hoffman AF, Sherling MA, Lupica CR, Hoffer BJ, Spenger C, Josephson A, Brené S, Olson L (2009) Nogo receptor 1 regulates formation of lasting memories. Proc Natl Acad Sci U S A 106:20476-20481.

Katz LC, Shatz CJ (1996) Synaptic activity and the construction of cortical circuits. Science 274:1133-1138.

Kelleher RJ 3rd, Govindarajan A, Jung HY, Kang H, Tonegawa S (2004) Translational control by MAPK signaling in long-term synaptic plasticity and memory. Cell 116:467-479.

Korte M, Carroll P, Wolf E, Brem G, Thoenen H, Bonhoeffer T (1995) Hippocampal long-term potentiation is impaired in mice lacking brainderived neurotrophic factor. Proc Natl Acad Sci U S A 92:8856-8860.

Kwon BK, Liu J, Lam C, Plunet W, Oschipok LW, Hauswirth W, Di Polo A, Blesch A, Tetzlaff W (2007) Brain-derived neurotrophic factor gene transfer with adeno-associated viral and lentiviral vectors prevents rubrospinal neuronal atrophy and stimulates regeneration-associated gene expression after acute cervical spinal cord injury. Spine 32:1164-1173.
Lee H, Raiker SJ, Venkatesh K, Geary R, Robak LA, Zhang Y, Yeh HH, Shrager P, Giger RJ (2008) Synaptic function for the Nogo-66 receptor NgR1: regulation of dendritic spine morphology and activity-dependent synaptic strength. J Neurosci 28:2753-2765.

Lee JK, Case LC, Chan AF, Zhu Y, Tessier-Lavigne M, Zheng B (2009) Generation of an OMgp allelic series in mice. Genesis 47:751-756.

Lee JK, Geoffroy CG, Chan AF, Tolentino KE, Crawford MJ, Leal MA, Kang B, Zheng B (2010) Assessing spinal axon regeneration and sprouting in Nogo-, MAG-, and OMgp-deficient mice. Neuron 66:663-670.

Lee KF, Li E, Huber LJ, Landis SC, Sharpe AH, Chao MV, Jaenisch R (1992) Targeted mutation of the gene encoding the low affinity NGF receptor p75 leads to deficits in the peripheral sensory nervous system. Cell 69:737-749.

Lee TH, Kato H, Pan LH, Ryu JH, Kogure K, Itoyama Y (1998) Localization of nerve growth factor, trkA and P75 immunoreactivity in the hippocampal formation and basal forebrain of adult rats. Neuroscience 83:335-349.

Lisman J (2003) Actin's actions in LTP-induced synapse growth. Neuron 38:361-362.

Lu Y, Christian K, Lu B (2008) BDNF: a key regulator for protein synthesis-dependent LTP and long-term memory? Neurobiol Learn Mem 89:312-323.

Maier IC, Baumann K, Thallmair M, Weinmann O, Scholl J, Schwab ME (2008) Constraint-induced movement therapy in the adult rat after unilateral corticospinal tract injury. J Neurosci 28:9386-9403.

Manning BD, Tee AR, Logsdon MN, Blenis J, Cantley LC (2002) Identification of the tuberous sclerosis complex-2 tumor suppressor gene product tuberin as a target of the phosphoinositide 3-kinase/akt pathway. Mol Cell 10:151-162.

Maya Vetencourt JF, Sale A, Viegi A, Baroncelli L, De Pasquale R, O’Leary OF, Castrén E, Maffei L (2008) The antidepressant fluoxetine restores plasticity in the adult visual cortex. Science 320:385-388.

McGee AW, Yang Y, Fischer QS, Daw NW, Strittmatter SM (2005) Experience-driven plasticity of visual cortex limited by myelin and Nogo receptor. Science 309:2222-2226.

Meng Y, Zhang Y, Jia Z (2003) Synaptic transmission and plasticity in the absence of AMPA glutamate receptor GluR2 and GluR3. Neuron 39:163-176.

Park KK, Liu K, Hu Y, Smith PD, Wang C, Cai B, Xu B, Connolly L, Kramvis I, Sahin M, He Z (2008) Promoting axon regeneration in the adult CNS by modulation of the PTEN/mTOR pathway. Science 322:963-966.

Phillips GR, Huang JK, Wang Y, Tanaka H, Shapiro L, Zhang W, Shan WS, Arndt K, Frank M, Gordon RE, Gawinowicz MA, Zhao Y, Colman DR (2001) The presynaptic particle web: ultrastructure, composition, dissolution, and reconstitution. Neuron 32:63-77.

Pizzorusso T, Medini P, Berardi N, Chierzi S, Fawcett JW, Maffei L (2002) Reactivation of ocular dominance plasticity in the adult visual cortex. Science 298:1248-1251.

Potter CJ, Pedraza LG, Xu T (2002) Akt regulates growth by directly phosphorylating Tsc2. Nat Cell Biol 4:658-665.

Rex CS, Lin CY, Kramár EA, Chen LY, Gall CM, Lynch G (2007) Brainderived neurotrophic factor promotes long-term potentiation-related cytoskeletal changes in adult hippocampus. J Neurosci 27:3017-3029.

Robak LA, Venkatesh K, Lee H, Raiker SJ, Duan Y, Lee-Osbourne J, Hofer T, Mage RG, Rader C, Giger RJ (2009) Molecular basis of the interactions of the Nogo-66 receptor and its homolog NgR2 with myelin-associated glycoprotein: development of NgROMNI-Fc, a novel antagonist of CNS myelin inhibition. J Neurosci 29:5768-5783.

Romero MI, Lin L, Lush ME, Lei L, Parada LF, Zhu Y (2007) Deletion of Nf1 in neurons induces increased axon collateral branching after dorsal root injury. J Neurosci 27:2124-2134.

Roux PP, Colicos MA, Barker PA, Kennedy TE (1999) p75 neurotrophin receptor expression is induced in apoptotic neurons after seizure. J Neurosci 19:6887-6896.

Schubert V, Dotti CG (2007) Transmitting on actin: synaptic control of dendritic architecture. J Cell Sci 120:205-212.

Schulz PE, Cook EP, Johnston D (1994) Changes in paired-pulse facilitation suggest presynaptic involvement in long-term potentiation. J Neurosci 14:5325-5337.

Sojka DK, Hughson A, Sukiennicki TL, Fowell DJ (2005) Early kinetic window of target $\mathrm{T}$ cell susceptibility to CD25 + regulatory $\mathrm{T}$ cell activity. J Immunol 175:7274-7280.

Sugaya K, Greene R, Personett D, Robbins M, Kent C, Bryan D, Skiba E, 
Gallagher M, McKinney M (1998) Septo-hippocampal cholinergic and neurotrophin markers in age-induced cognitive decline. Neurobiol Aging 19:351-361.

Sweatt JD (2004) Mitogen-activated protein kinases in synaptic plasticity and memory. Curr Opin Neurobiol 14:311-317.

Syken J, Shatz CJ (2003) Expression of T cell receptor beta locus in central nervous system neurons. Proc Natl Acad Sci U S A 100:13048-13053.

Syken J, Grandpre T, Kanold PO, Shatz CJ (2006) PirB restricts oculardominance plasticity in visual cortex. Science 313:1795-1800.

Takai T (2005) Paired immunoglobulin-like receptors and their MHC class I recognition. Immunology 115:433-440.

Takamura H, Ichisaka S, Hayashi C, Maki H, Hata Y (2007) Monocular deprivation enhances the nuclear signalling of extracellular signal-regulated kinase in the developing visual cortex. Eur J Neurosci 26:2884-2898.

Thomas GM, Huganir RL (2004) MAPK cascade signalling and synaptic plasticity. Nat Rev Neurosci 5:173-183.

Tropea D, Van Wart A, Sur M (2009) Molecular mechanisms of experiencedependent plasticity in visual cortex. Philos Trans R Soc Lond B Biol Sci 364:341-355.

Tsokas P, Grace EA, Chan P, Ma T, Sealfon SC, Iyengar R, Landau EM, Blitzer $\mathrm{RD}$ (2005) Local protein synthesis mediates a rapid increase in dendritic elongation factor $1 \mathrm{~A}$ after induction of late long-term potentiation. J Neurosci 25:5833-5843.

Tsokas P, Ma T, Iyengar R, Landau EM, Blitzer RD (2007) Mitogenactivated protein kinase upregulates the dendritic translation machinery in long-term potentiation by controlling the mammalian target of rapamycin pathway. J Neurosci 27:5885-5894.

Ujike A, Takeda K, Nakamura A, Ebihara S, Akiyama K, Takai T (2002) Impaired dendritic cell maturation and increased $\mathrm{T}(\mathrm{H}) 2$ responses in PIR-B(-/-) mice. Nat Immunol 3:542-548.

Vaynman S, Gomez-Pinilla F (2005) License to run: exercise impacts functional plasticity in the intact and injured central nervous system by using neurotrophins. Neurorehabil Neural Repair 19:283-295.
Venkatesh K, Chivatakarn O, Lee H, Joshi PS, Kantor DB, Newman BA, Mage R, Rader C, Giger RJ (2005) The Nogo-66 receptor homolog NgR2 is a sialic acid-dependent receptor selective for myelin-associated glycoprotein. J Neurosci 25:808-822.

Venkatesh K, Chivatakarn O, Sheu SS, Giger RJ (2007) Molecular dissection of the myelin-associated glycoprotein receptor complex reveals cell typespecific mechanisms for neurite outgrowth inhibition. J Cell Biol 177:393-399.

Wang X, Chun SJ, Treloar H, Vartanian T, Greer CA, Strittmatter SM (2002) Localization of Nogo-A and Nogo-66 receptor proteins at sites of axonmyelin and synaptic contact. J Neurosci 22:5505-5515.

Wang Y, Cheng A, Mattson MP (2006) The PTEN phosphatase is essential for long-term depression of hippocampal synapses. Neuromolecular Med 8:329-336.

Woo NH, Teng HK, Siao CJ, Chiaruttini C, Pang PT, Milner TA, Hempstead BL, Lu B (2005) Activation of p75NTR by proBDNF facilitates hippocampal long-term depression. Nat Neurosci 8:1069-1077.

Xie F, Zheng B (2008) White matter inhibitors in CNS axon regeneration failure. Exp Neurol 209:302-312.

Yiu G, He Z (2006) Glial inhibition of CNS axon regeneration. Nat Rev Neurosci 7:617-627.

Yuste R, Bonhoeffer T (2001) Morphological changes in dendritic spines associated with long-term synaptic plasticity. Annu Rev Neurosci 24:1071-1089.

Zagrebelsky M, Holz A, Dechant G, Barde YA, Bonhoeffer T, Korte M (2005) The p75 neurotrophin receptor negatively modulates dendrite complexity and spine density in hippocampal neurons. J Neurosci 25:9989-9999.

Zheng B, Atwal J, Ho C, Case L, He XL, Garcia KC, Steward O, Tessier-Lavigne M (2005) Genetic deletion of the Nogo receptor does not reduce neurite inhibition in vitro or promote corticospinal tract regeneration in vivo. Proc Natl Acad Sci U S A 102:1205-1210.

Zhou L, Shine HD (2003) Neurotrophic factors expressed in both cortex and spinal cord induce axonal plasticity after spinal cord injury. J Neurosci Res 74:221-226. 